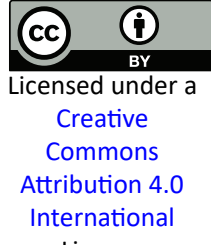

License

\title{
Gradient dissimilation in Mongolian: Implications for diachrony
}

\author{
ADÈlE JATTEAU \\ Université Paris 8
}

\author{
Michaela Hejná \\ Aarhus University
}

\begin{abstract}
This paper explores the implications of 'gradient dissimilation' (Jatteau \& Hejná 2016) for the diachronic implementation of long-distance dissimilation (e.g. $\mathrm{C}^{\mathrm{h}} \mathrm{VC}^{\mathrm{h}}>\mathrm{CVC}^{\mathrm{h}}$ ). Since dissimilation is usually considered lexically sporadic, cases where it applies regularly throughout the lexicon should result from lexical diffusion. Against this assumption, we explore the hypothesis that gradient dissimilation may represent the phonetic precursor of completed, regular dissimilatory processes. Such cases might then be reanalysed as Neogrammarian types of change. To assess this question, we gather and analyse new data from Halh Mongolian, a language reported to show gradient dissimilation of the aspiration feature, and compare it to two completed patterns of aspiration dissimilation reconstructed within the Mongolic family: Chahar Mongolian and Monguor. The results suggest that the gradient dissimilation in Halh may represent the phonetic precursor of Chahar, but also that gradient dissimilation may be bidirectional for some speakers. An interesting difference between our Halh Mongolian results and the other patterns of the Mongolic family resides in the behaviour of /s/, which in our data does not pattern as expected with the aspirated stops.
\end{abstract}

Or take Grassmann's law, so-called. (...) There is absolutely no reason why the champions of graduality could not have this deaspiration occur in a perfectly gradual manner. (Hoenigswald 1964, 209)

\section{What type of change is dissimilation?}

\subsection{Dissimilation in the typology of sound changes}

Dissimilation is a process whereby two similar segments become less similar in a given domain. A famous example is Grassmann's Law in Ancient Greek: in roots containing two aspirated segments, the first one lost its aspiration feature. 
(1) Grassmann's Law in Ancient Greek

${ }^{*} t^{h}$ rep $^{h}{ }_{\mathrm{J}}$ > trep $^{h}{ }_{\mathrm{J}:}$ 'cause to grow'

In this paper, we will be concerned only with long-distance dissimilation, that is, between non-contiguous segments. As underlined by Bennett (2015, 317-321), dissimilation between contiguous and noncontiguous segments is subject to different types of phonetic pressures, and may thus arise through partly different mechanisms. ${ }^{1}$

Beginning with the Neogrammarians (Osthoff \& Brugmann 1878; Paul 1920), most typologies exclude dissimilation from the core category of sound changes. ${ }^{2}$ Classical 'Neogrammarian' types of change are expected to be lexically regular, phonetically gradient, and amenable to 'mechanical' articulatory mechanisms (Osthoff \& Brugmann 1878; BermúdezOtero 2007). In contrast, dissimilation may fail to fill all of these criteria.

The first, most salient property of dissimilation is that it can be very sporadic, affecting only a small number of words in the lexicon. The 'Limited Grassmann's Law' in Latin, for example, happened in a couple of words.

(2) 'Limited Grassmann's Law' in Latin (Weiss 2009, 156)

${ }^{*} b^{h} a r d^{h} e h_{2}>b a r b a$, instead of expected **farba 'beard'

Dissimilation, however, can also be fully regular, as in the Greek case in (1). It may then be described from a synchronic point of view as a cooccurrence restriction on a given feature within a certain domain (Suzuki 1998; MacEachern 1999; Bennett 2015). An example is Quechua, which allows at most one ejective per word, as a result of a diachronic dissimilation of ejective features (as in 't'ant'a > t'anta 'bread', Orr \& Longacre 1968, 549; Gallagher 2010); Gallagher (2016) shows that the rule is productive in psycholinguistic experiments.

The second difference with the classical Neogrammarian type of change is categoricity. If dissimilation is a sporadic change, then it must be phonetically categorical: the dissimilated feature should be deleted at once, rather than progressively reduced. ${ }^{3}$ For instance, $t^{\prime} a n t^{\prime} a$ would be

\footnotetext{
${ }^{1}$ For example, the explanation of dissimilation in CC clusters may involve the masking of $\mathrm{C}_{1}$ release by $\mathrm{C}_{2}$, while this factor does not affect CVC sequences.

${ }^{2}$ For example Bloomfield (1933), Kiparsky (1995), Hock \& Joseph (2009); see the overview in Garrett \& Johnson (2013).

${ }^{3}$ Cf. Kiparsky (1995), Hock \& Joseph $(2009,108)$. Paul $(1920, \S 45)$ for example describes dissimilation as a Vertauschung, a '(sound) transposition', rather than a Lautwandel 'sound change'; Bloomfield $(1933,390)$ calls it a 'replacement'.
} 
abruptly replaced by t'anta, rather than gradiently evolving towards it. As far as we know however, no instance of dissimilation has ever been directly observed which confirms this assumption.

Finally, the last reason why dissimilation looks 'different' is its very mechanism: why would two distant sounds become less similar? The process is especially difficult to explain when compared to its opposite, assimilation. In Zulu for example, two stops within the same root must share the same laryngeal feature (Gallagher 2010). Such processes may be related to coarticulatory phenomena. But then, as Ohala $(1987,215$ 216) puts it, 'How can we suggest with a straight face that it is natural both for sounds unlike to become more similar and also for similar sounds to become less similar?'

Based on the literature, dissimilation cannot then qualify as a Neogrammarian sound change: it can be sporadic, it is assumed to be phonetically abrupt, and does not obey any obvious phonetic mechanism. The question is then why, in certain languages, it is completely regular and productive.

(3) Type 1: completed (the feature has disappeared), sporadic e.g. Latin in (2)

Type 2: completed (the feature has disappeared), regular e.g. Ancient Greek in (1)

Although this is not explicitly stated in the literature, the fact that dissimilation can be sporadic or regular suggests it may undergo another type of sound change mechanism: lexical diffusion (Bermúdez-Otero 2007). Dissimilation would first happen in a handful of words, as instantiated for example by the Latin case in (2) (Type 1 above), and may then spread word by word throughout the lexicon. Co-occurrence restrictions, as in Ancient Greek in (1) or Quechua (Type 2 above), would attest the final stage of the change, where all words of the lexicon have undergone the dissimilation.

\subsection{Gradient dissimilation}

Recent studies have however revealed the existence of a third type of dissimilation, with very different properties, which we have called 'gradient dissimilation' (Jatteau \& Hejná 2016). This term designates a synchronic process whereby a feature is not deleted, but reduced in duration, when it appears in the vicinity of a similar feature. It has been reported so far for the aspiration feature in three different languages: Halh Mongolian, Aberystwyth English and Georgian. 
The first reported case is Halh Mongolian (Svantesson et al. 2005, Svantesson \& Karlsson 2012). Halh Mongolian is a pre-aspirating language: fortis stops are pre-aspirated in all positions except when postpausal (Svantesson et al. 2005, 14). In ChC- words, the VOT of the first aspirated consonant is shorter when the second consonant of the word is an aspirated stop or /s/, as in (4)a, than when the second consonant is a sonorant, as in (4)b.

(4) Average VOT of $\mathrm{C}_{1}$ in Halh Mongolian (Svantesson et al. 2005)
a. $\left[\mathrm{t}^{\mathrm{h}} \mathrm{a}^{\mathrm{h}} \operatorname{tax}\right]$ 'to pull' $50 \mathrm{~ms}$
[ $\left.\underline{\mathrm{t}^{\mathrm{h}}} \mathrm{\textrm {os }}\right] \quad$ 'fat' $49 \mathrm{~ms}$

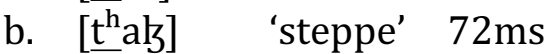

This is a type of dissimilation, because an aspiration feature is affected specifically in the presence of another aspiration feature, and it is regressive: the first aspiration feature is reduced when another one follows. It should be borne in mind though that the properties of the aspiration feature of $\mathrm{C}_{2}$ have not been investigated so far. This means that we could in fact be dealing with a bidirectional process. Crucially, the dissimilatory effect is gradient, since the feature is not categorically deleted, but gradiently reduced in duration. The behaviour of /s/ as an aspirated consonant in [ $\mathrm{t}^{\mathrm{h}} \mathrm{J}$ ] is consistent with the phonology of Mongolian: /s/ is pronounced with post-aspiration in initial and medial positions (Svantesson et al. 2005,18), and patterns with the aspirated stops in a number of phonological processes (cf. Section 1.3).

A problem with the Mongolian pattern is that it is based on little evidence: measurements are available for only one speaker, repeating the three words four times each (Svantesson \& Karlsson 2012). Moreover, the three words in (4) have different syllabic structures, which may have an impact on aspiration duration.

Nevertheless, our own previous work has found gradient dissimilation in another language, where a much bigger and balanced corpus was available: Aberystwyth English (Jatteau \& Hejná 2016). In contrast to the Halh evidence, the Aberystwyth corpus includes more than 7000 words, spoken by 12 speakers. In this variety of English, spoken in Wales, fortis stops are both pre- and post-aspirated in medial position (Hejná 2015). For this data, our study (Jatteau \& Hejná 2016) found that the pre-aspiration feature of the second stop in $\mathrm{CVC}^{\mathrm{h}}$ - words is consistently reduced when the first stop is an aspirated consonant, that is, an aspirate stop or /h/ (as in (5)a), as opposed to when the first consonant is a lenis stop or a sonorant (as in (5)b). 
(5) Average duration of the pre-aspiration of $\mathrm{C}_{2}$ in Aberystwyth English $^{4}$ (Jatteau \& Hejná 2016)

$\begin{array}{llll}\text { a. patter } & {\left[\mathrm{p}^{\mathrm{h}} \mathrm{a}^{\mathrm{h}} \mathrm{t}^{\mathrm{h}} \mathrm{\partial}\right.} & 26 \mathrm{~ms} \\ \text { b. } & \text { batter } & {\left[\mathrm{ba}^{\mathrm{h}^{\mathrm{h}}} \mathrm{t}\right.} & 40 \mathrm{~ms} \\ & \text { latter } & {\left[\mathrm{la} \mathrm{a}^{\mathrm{h}} \mathrm{t}^{\mathrm{h}} \mathrm{\partial}\right.} & 36 \mathrm{~ms}\end{array}$

In this case, the dissimilation is progressive: the second aspiration feature of the word is reduced when another aspirated stop precedes. As in Halh however, only one of the two consonants has been investigated so far. In addition, we have shown that the pattern is lexically regular: it does not depend on lexical frequency.

Finally, Beguš (2016) found evidence for a progressive, gradient dissimilation pattern in Georgian. This third language is interesting because, contrary to Mongolian and Welsh English, it involves post-aspiration rather than both pre- and post-aspiration. Nevertheless, the study shows preliminary results, and needs to be confirmed with a more balanced dataset.

To summarize, there are then not two, but three types of dissimilation.

(6) Type 1: completed (the feature has disappeared), sporadic e.g. Latin in (2)

Type 2: completed (the feature has disappeared), regular e.g. Ancient Greek in (1)

Type 3: gradient (the feature is reduced), regular e.g. Aberystwyth English in (5)

Type 3 has interesting implications for diachrony. If dissimilation can also surface as a lexically regular and phonetically gradient process, could it evolve into a lexically regular and phonetically gradient sound change, that is, a 'Neogrammarian' type of change? The hypothesis would be that one aspiration feature in $\mathrm{C}^{\mathrm{h}} \mathrm{VC}$ - sequences is progressively reduced until it disappears completely (Garrett 2015). If such a process could happen, then (some cases of) dissimilation could be integrated within the main category of sound changes: the regular co-occurrence restrictions in Ancient Greek and Quechua may be accounted for not as results of lexical diffusion, but of Neogrammarian changes. In order to investigate this hypothesis, the goal of this paper is to explore the following question: could

${ }^{4}$ The reader is referred to Hejná (2016) for more details on the phonetic implementation of the fortis-lenis plosive contrast in Aberystwyth English. 
gradient dissimilation (Type 3 above) be the phonetic precursor of complete, regular dissimilation (Type 2 above)?

\subsection{Dissimilation in Mongolian}

Interestingly, Mongolian seems to support this hypothesis: within the Mongolic family, two types of completed dissimilation patterns are attested. The first one is regressive, and exemplified by Chahar Mongolian (Section 1.3.1); the second is progressive, and appears in the related Mongolic language Monguor (Section 1.3.2). The question is then whether the gradient process in Halh preserves the phonetic precursor of one or both of these completed dissimilatory patterns (Section 1.4).

\subsubsection{The Chahar Mongolian type}

In a wide dialectal area including Southern Mongolia and the autonomous region of Mongolia in China, the first aspiration feature of $\mathrm{C}^{\mathrm{h}} \mathrm{VC}^{\mathrm{h}}$ - sequences has completely disappeared. ${ }^{5}$ The dissimilatory pattern is exemplified in Table 1 by the Chahar dialect. Note that [x] is the expected reflex of Old Mongolian ${ }^{*} k^{h}$.

\begin{tabular}{|c|c|c|c|c|}
\hline & Old Mongolian & Chahar & Halh & \\
\hline a. & $* t^{h} a t^{h} a$ & tat $^{\mathrm{h}}$ & $\mathrm{t}^{\mathrm{h}} \mathrm{at} \mathrm{t}^{\mathrm{h}}$ & 'to pull' \\
\hline & $* \mathrm{k}^{\mathrm{h}} \emptyset \mathrm{k}^{\mathrm{h}} \mathrm{e}$ & kox & XOX & 'blue' \\
\hline b. & $*^{\mathrm{h}} \mathrm{h}$ osun & tos & $\mathrm{t}^{\mathrm{h}} \mathrm{\partial s}$ & 'fat' \\
\hline c. & $\begin{array}{l}{ }^{*} \mathrm{k}^{\mathrm{h}} \text { aut }{ }^{\mathrm{h}} \text { in } \\
{ }^{*} \mathrm{k}^{\mathrm{h}} \mathrm{amt}^{\mathrm{h}} \mathrm{u}\end{array}$ & 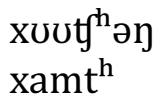 & $\begin{array}{l}\text { xuvth }{ }^{h} ә \eta \\
\text { xamt }^{h}\end{array}$ & $\begin{array}{l}\text { 'old' } \\
\text { 'together' }\end{array}$ \\
\hline
\end{tabular}

Table 1: The pattern of completed, regressive dissimilation in Chahar

The Chahar pattern of dissimilation is very similar to the Halh pattern reported by Svantesson et al. (2005), and presented above in section 1.2 - except that in Chahar the aspiration feature is deleted, while in Halh it is only reduced in duration. First, both are regressive dissimilations: the realisation of the first aspiration feature depends on the presence of a second one. Second, they involve the same segments: dissimilation is

\footnotetext{
${ }^{5}$ Cf. Svantesson et al. $(2005,205-206)$; a map of the Mongolian dialects according to Svantesson et al. is available on p. 141.
} 
triggered by aspirated stops, as in Table $1 \mathrm{a}$, and /s/, as in Table $1 \mathrm{~b}$. Chahar Mongolian shows an interesting asymmetry in this respect: /s/ triggers, but does not undergo dissimilation. As noted in section $1.2 \mathrm{e} / \mathrm{s} /$ is phonetically post-aspirated in Halh Mongolian; ${ }^{6}$ we do not know whether this description extends to Chahar and related dialects. It should be noted that fricatives in Mongolian do not contrast for laryngeal features. Finally, the Chahar dissimilation holds only over a short vowel: both aspiration features are preserved when they are separated by a long vowel, a diphthong or a coda consonant (cf. Table 1c). This makes the Chahar pattern a very interesting case of non-adjacent dissimilation: it is the only case sensitive to the mora we know of. ${ }^{7}$

The question is then the following: could the Halh dialect reflect the incipient stage of a process which was completed in Chahar? In this case, we may expect the two patterns to be parallel. First, they should show similar sets of triggers and undergoers. Second, we may expect the gradient dissimilation pattern to apply within a limited domain, that is, to apply in $\underline{\mathrm{C}}^{\mathrm{h}} \mathrm{VC}^{\mathrm{h}}$ - as opposed to $\underline{\mathrm{C}}^{\mathrm{h}} \mathrm{VXC} \mathrm{C}^{\mathrm{h}}$-. This information, however, is not available in the literature.

\subsubsection{The Monguor type}

What makes the Mongolian case even more interesting is that a second type of dissimilation is attested within the Mongolic family. Monguor is a sister language of Mongolian, spoken in the Gansu-Qinghai region of China (Svantesson et al. 2005, 151-152). Like most Mongolian dialects, this language has developed a dissimilation pattern. In this case however, dissimilation is progressive, as illustrated in Table 2 (Mostaert \& de Smedt 1930; Georg 2003, Svantesson et al. 2005).

The process applied regularly in Monguor. It also appears irregularly in the neighbouring Santa and Bonan languages; a few words also show dissimilation in Kangjia and Shira Yugur (Svantesson et al. 2005, 206-207). The Monguor pattern differs from the Chahar one in a number of features. First, it is a case of progressive dissimilation: the second aspirated consonant loses its aspirated feature, not the first one. Second, the set of triggers includes the aspirated stops, /s/, but also /h/ (cf. Table 2b; no me-

\footnotetext{
${ }^{6}$ According to Svantesson et al. $(2005,18), / \int /$ is also phonetically post-aspirated in Halh.

${ }^{7}$ See the list of dissimilatory patterns in the online supplement to Bennett (2015), and more specifically on aspiration Jatteau (2016, 567-571).
} 


\begin{tabular}{|c|c|c|c|c|}
\hline & Old Mongolian & Monguor & Halh & \\
\hline a. & $* \mathrm{t}^{\mathrm{h}} \mathrm{at}{ }^{\mathrm{h}} \mathrm{a}$ & $\mathrm{t}^{\mathrm{h}}$ ita & $\mathrm{t}^{\mathrm{h}} \mathrm{at} \mathrm{t}^{\mathrm{h}}$ & 'to pull' \\
\hline & ${ }^{*} \mathrm{k}^{\mathrm{h}} \varnothing \mathrm{k}^{\mathrm{h}} \mathrm{e}$ & $\mathrm{k}^{\mathrm{h}}$ uko & XOX & 'blue' \\
\hline b. & ${ }^{*} \operatorname{syk}^{\mathrm{h}} \mathrm{e}$ & suko & sux & 'axe' \\
\hline & ${ }^{*}$ hyk $^{\mathrm{h}} \mathrm{er}$ & xukor & uxer & 'ox' \\
\hline c. & $\begin{array}{l}{ }^{*} \mathrm{k}^{\mathrm{h}} \operatorname{autt}^{\mathrm{h}} \text { in } \\
{ }^{*} \mathrm{k}^{\mathrm{h}} \operatorname{amt}^{\mathrm{h}} \mathrm{u}\end{array}$ & $\begin{array}{l}\text { xautfin } \\
\text { xamti }\end{array}$ & 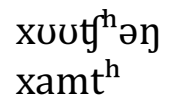 & $\begin{array}{l}\text { 'old' } \\
\text { 'together' }\end{array}$ \\
\hline
\end{tabular}

Table 2: The pattern of completed, progressive dissimilation in Monguor

dial / $\mathrm{h} /$ is preserved in Chahar). ${ }^{8}$ Another difference is that the domain of dissimilation is wider: as shown by the examples in Table 2c, complex rhymes do not block dissimilation. According to Georg $(2003,292)$, the domain of the synchronic co-occurrence restriction is the stem.

Finally, the language shows what MacEachern (1999) labelled a 'leftness effect': the aspirated stop must be the first stop in the word. This results from the progressive dissimilation process conspiring with a pattern of leftward aspiration metathesis (Table 3). This aspiration 'flip-flop' (Svantesson et al. 2005, 207) can be triggered by /s/, and created in some cases a word-initial $/ \mathrm{p}^{\mathrm{h}} /$ phoneme (cf. Table $3 \mathrm{~b}$ ). When the word began with a vowel, a word-initial /h/ was inserted (here noted as $x$, cf. Table $3 c)^{9}$

\begin{tabular}{llll}
\hline & Old Mongolian & Monguor & \\
\hline a. & *tot ${ }^{\mathrm{h}}$ ara & $\mathrm{t}^{\mathrm{h}}$ utor & 'inside' \\
b. & *pyse & $\mathrm{p}^{\mathrm{h}}$ usee & 'belt' \\
c. & *alt ${ }^{\mathrm{h}}$ an & xaltan & 'gold' \\
\hline
\end{tabular}

Table 3: Regressive aspiration metathesis in Monguor

\footnotetext{
${ }^{8}$ According to Mostaert \& de Smedt (1930), dissimilation in Monguor can also be triggered by /f/ and /x/; it is not clear how regularly this is the case.

${ }^{9}$ A similar conspiration may have occurred in Harauthi, which also displays a cooccurrence restriction and a 'leftness effect' (Allen 1957). Leftward aspiration metathesis coexists however with regressive dissimilation in the history of Ancient Greek (Lejeune 1972; Jatteau 2016) and Basque (Egurtzegi 2015).
} 
Two different types of complete dissimilation are then attested within the same language family, in opposite directions: regressive in Mongolian dialects, progressive in Monguor. What could be the common ancestor of these opposite patterns? The Halh process of gradient dissimilation might provide an interesting answer to this question. If a pattern of gradient dissimilation in Old Mongolian affected both aspiration features in $\mathrm{C}^{\mathrm{h}} \mathrm{VC}^{\mathrm{h}}$ sequences, we could make the hypothesis that different branches of the language family targeted different sides of the aspiration reduction: Chahar and related dialects would have amplified the dissimilation of $\mathrm{C}_{1}$, resulting in complete regressive dissimilation, and Monguor would have amplified the dissimilation of $\mathrm{C}_{2}$, resulting in complete progressive dissimilation. The question then is whether such a bidirectional process is possible. As mentioned in section 1.2 however, previous accounts of gradient dissimilation focussed on only one of the two consonants involved in the dissimilation.

\subsection{Research questions}

To summarize, the discovery of a synchronic, lexically regular and phonetically gradient type of dissimilation may allow us to refine the traditional analysis of this process in diachrony: lexically regular cases of completed dissimilation may be reanalysed as Neogrammarian changes, through the progressive reduction of one of the dissimilated features. The Mongolic family is a good place to test this hypothesis: three different types of dissimilation are attested in different branches (Table 4 on p. 37). ${ }^{10}$

Could the Halh pattern reflect the phonetic precursor of one or both of the other patterns? Three scenarios are possible. First, gradient dissimilation could be an independant development of the Halh dialect of Mongolian, and have nothing to do with the completed dissimilations in Chahar and Monguor. Alternatively, gradient dissimilation could be an innovation of the Mongolian branch, and the precursor of the Chahar dissimilation only. Finally, the Halh pattern could preserve an Old Mongolian stage, which later evolved into progressive dissimilation in one branch, and regressive dissimilation in another one. In this third case, we should be able to find evidence of both regressive and progressive dissimilation in Halh Mongolian. To evaluate these scenarios, we propose to apply the

\footnotetext{
10 There are four if we include the sporadic patterns in Santa, Bonan, Kangjia and Shira Yugur (cf. Section 1.3.2). If the Monguor dissimilation arose through a Neogrammarian sound change, as hypothesized in this paper, these cases would be analysed as borrowings through the contact with Monguor.
} 


\begin{tabular}{|c|c|c|}
\hline \multicolumn{3}{|c|}{ Old Mongolian } \\
\hline \multicolumn{2}{|c|}{ Mongolian } & \multirow[t]{2}{*}{ Monguor } \\
\hline Halh & Chahar & \\
\hline $\begin{array}{ll}\text { - } & \text { synchronic } \\
\text { - } & \text { phonetically } \\
\text { gradient } \\
\text { - } & \text { regressive } \\
& \text { (only?) } \\
\text { - } & \text { domain? }\end{array}$ & $\begin{array}{ll}\text { - } & \text { diachronic } \\
\text { - } & \text { phonetically } \\
\text { - } & \text { categorical } \\
\text { - } & \text { overessive } \\
& \text { vowels }\end{array}$ & $\begin{array}{ll}\text { - } & \text { diachronic } \\
\text { - } & \text { phonetically } \\
\text { - } & \text { categorical } \\
\text { - } & \text { within the } \\
& \text { stem }\end{array}$ \\
\hline
\end{tabular}

Table 4: Three patterns of dissimilation in the Mongolic family

comparative method: we expect to find similar properties in gradient dissimilation and in the patterns which hypothetically derive from it. Three questions must then be investigated:

(7) 1. Is gradient dissimilation indeed attested in Halh, as described by Svantesson et al. (2005); Svantesson \& Karlsson (2012)?

- Is it regular across speakers? Is it regular across different word structures (mono- vs. polysyllables)? Do we find the same set of triggers and undergoers?

2. Could it show the phonetic precursor of the Chahar dissimilation pattern?

- Is it sensitive to the length of the intervening vowel?

3. Could it show the phonetic precursor of both the Chahar and Monguor dissimilatory patterns?

- Is it both regressive and progressive?

The problem is that very little is known of the Halh gradient dissimilation pattern: as mentioned in 1.2, the reported pattern is based on very limited evidence. To answer these questions, we gathered and analysed new data for Halh Mongolian. The next sections explain the methodology (Section 2) and results (Section 3). These results are discussed in Section 4; Section 5 concludes and sketches directions for further research. 


\section{Methodology}

This section provides information about the speakers analysed in this study (Section 2.1), the type of data collected and analysed (Section 2.2), as well as the quantification of the linguistic aspects of interest (Section 2.3).

\subsection{Speakers}

The analyses are based on 8 native speakers of Halh Mongolian (2 males, 6 females). These were all born and raised in Ulaanbaatar except one speaker from Erdenet (Northern Halh region), and one from Zavkhan (Southern Mongolia). A comparison of the production of these speakers did not reveal any individual specific differences in the presence and the direction of any potential dissimilatory patterns that would correlate with the geographic background of our speakers. ${ }^{11}$ The speakers were born between 1970 and 1980; they arrived in France between 2003 and 2014 and had very heterogeneous proficiency levels in French. The speakers were recorded with an H4 Zoom recorder, in conjunction with a headmounted AKG C520 microphone for two speakers (MN1, MN2).

\subsection{Data}

We obtained Mongolian words read in isolation from the eight speakers described above. These words represent a range of prosodic and segmental conditions.

Above all, we aimed to collect tokens with the four types of consonants in order to test for potential presence of regressive and/or progressive dissimilation patterns. These four types were a. sonorants, b. fortis plosives, c. lenis plosives, and d. /s/. We targeted words in which these occurred in word-initial position $\left(\mathrm{C}_{1}\right)$, word-medial position $\left(\mathrm{C}_{2}\right)$, and wordfinal position $\left(\mathrm{C}_{2}\right)$.

Next, to test for whether any dissimilatory patterns are blocked by phonologically long vowels, the words were chosen so that the intervening vowel set was comprised predominantly of /a/, /a:/, although we also collected some additional words with $/ \mathrm{J} /$, and $/ \mathrm{J}:$, because some comparisons of interest are not available in the language with /a/ (but unfortunately others are not available for $/ \mathrm{J} /$, which presents us with analytical problems).

${ }^{11}$ Cf. Sections 3.1.1 and 3.2.1 for details about the speaker from Southern Mongolia. 
In addition, the combinations of the selected consonants and vowels were collected primarily for words with monosyllabic and disyllabic prosodic structure (CVC, CVCV). This decision enables a comparison between our results and those reported previously (Svantesson et al. 2005, Svantesson \& Karlsson 2012) without the confound between prosody (number of syllables) and type of trigger.

The dataset analysed in this paper contains 376 monosyllabic, 856 disyllabic, and 65 trisyllabic words in total. ${ }^{12}$ The target combinations are summarised in Table 5 below. The complete wordlist is available in the Associated materials.

\begin{tabular}{cccc}
\hline $\begin{array}{c}\mathrm{C}_{2} \text { trigger } \\
\text { monosyllable }\end{array}$ & $\begin{array}{c}\mathrm{C}_{2} \text { trigger } \\
\text { disyllable }\end{array}$ & $\begin{array}{c}\mathrm{C}_{1} \text { trigger } \\
\text { monosyllable }\end{array}$ & $\begin{array}{c}\mathrm{C}_{1} \text { trigger } \\
\text { disyllable }\end{array}$ \\
\hline TVT & TVTV & TVT & TVTV \\
TVD & TVDV & DVT & DVTV \\
TVR & TVRV & RVT & RVTV \\
TVs & TVsV & sVT & sVTV \\
\hline
\end{tabular}

Table 5: Dataset. $\mathrm{T}$ = fortis stop; $\mathrm{D}=$ lenis stop; $\mathrm{R}=$ sonorant

\subsection{Acoustic analysis}

The data was annotated in Praat (Boersma \& Weenink 2017). Aspiration dissimilation was quantified via analyses of release duration (2.3.1), voiceless pre-aspiration (2.3.2), local breathiness (2.3.3), and the overall breathiness dynamics of the vowel (2.3.4). The identification and the quantification of these aspects are described in more detail in what follows.

\subsubsection{Release duration and post-aspiration}

The duration of the release was measured from the onset of the burst to the onset of the voicing associated with the following vowel in CVCV words. This was done for fortis and lenis plosives. For /s/, where postaspiration was present, its duration was measured as well. Furthermore,

\footnotetext{
12 The inclusion of three trisyllabic words (batalgaa 'guarantee', patentlax 'to patent', and sataarax 'to get distracted') was due to the non-existence of suitable disyllabic words in other comparisons of interest.
} 
in case of /s/ we also coded for whether post-aspiration is present or absent, which was not done for the plosive context. The reason is the following: when stops show a short release, it is not always possible to tell whether the release includes a post-aspiration period in addition to the burst. Post-aspiration could nevertheless be identified relatively straightforwardly in the case of /s/. Post-aspirated /s/ shows a period of voiceless glottal friction, which follows the oral release of the fricative. The oral friction of /s/ can be clearly distinguished from the glottal friction associated with post-aspiration, since the oral friction exhibits most energy in higher frequencies, unlike glottal friction. Conveniently, /s/ is the only fricative in our potential triggers and undergoers and it is a phonological fricative which is spectrally most different from post- and preaspiration in the language. The identification and measurement of /s/ post-aspiration is illustrated in Figure 1.

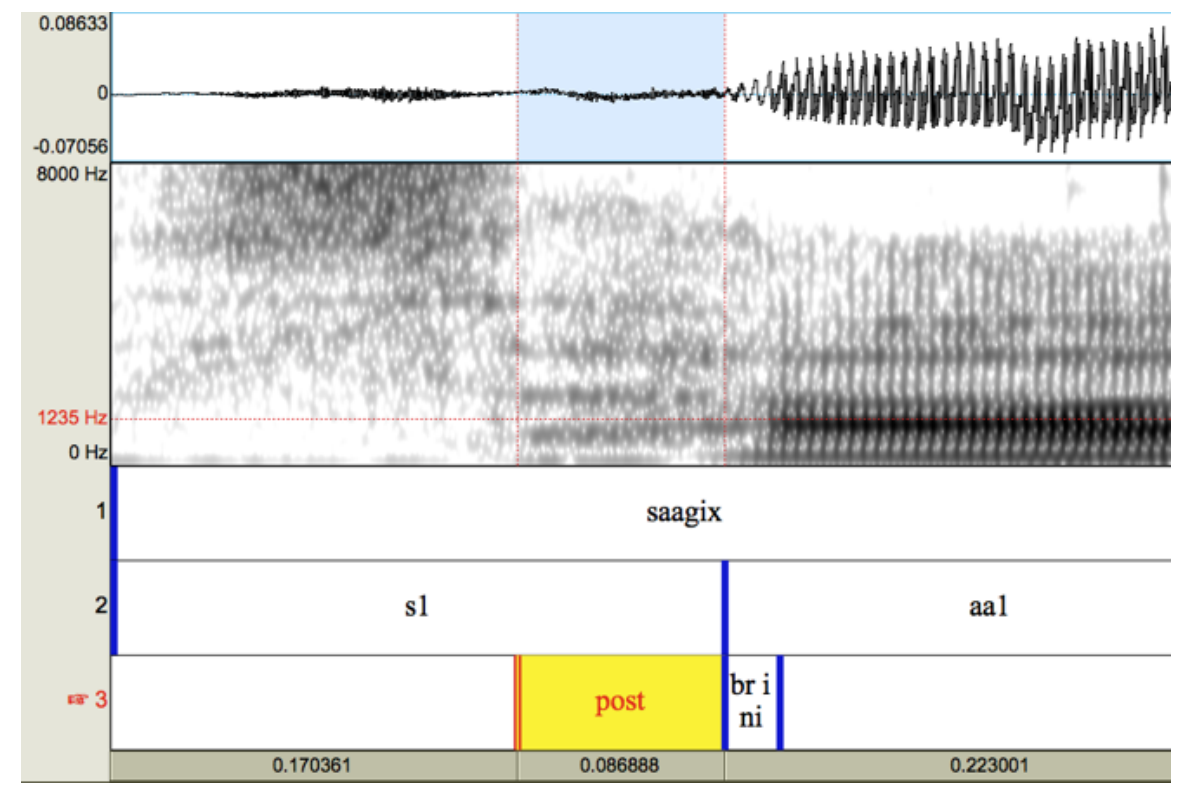

Figure 1: Post-aspiration in the word saagix 'to swirl (smoke)'. 'br ini' = breathiness caused by preceding release.

\subsubsection{Pre-aspiration}

We follow Jatteau \& Hejná (2016), Kingston (1990), Morris \& Hejná (in press), Nance \& Stuart-Smith (2013), and Ní Chasaide (1985) in adopting a narrow definition of pre-aspiration as a period of voiceless (primarily) 
glottal friction found in the sequences of voiced sonorants and phonetically voiceless obstruents. The criteria for the identification follow those proposed in Hejná (2016). Firstly, pre-aspiration exhibits presence of friction found immediately prior to a plosive closure (in the context of plosives). This friction is voiceless, which defines the left boundary of pre-aspiration, as shown in Figure 2.

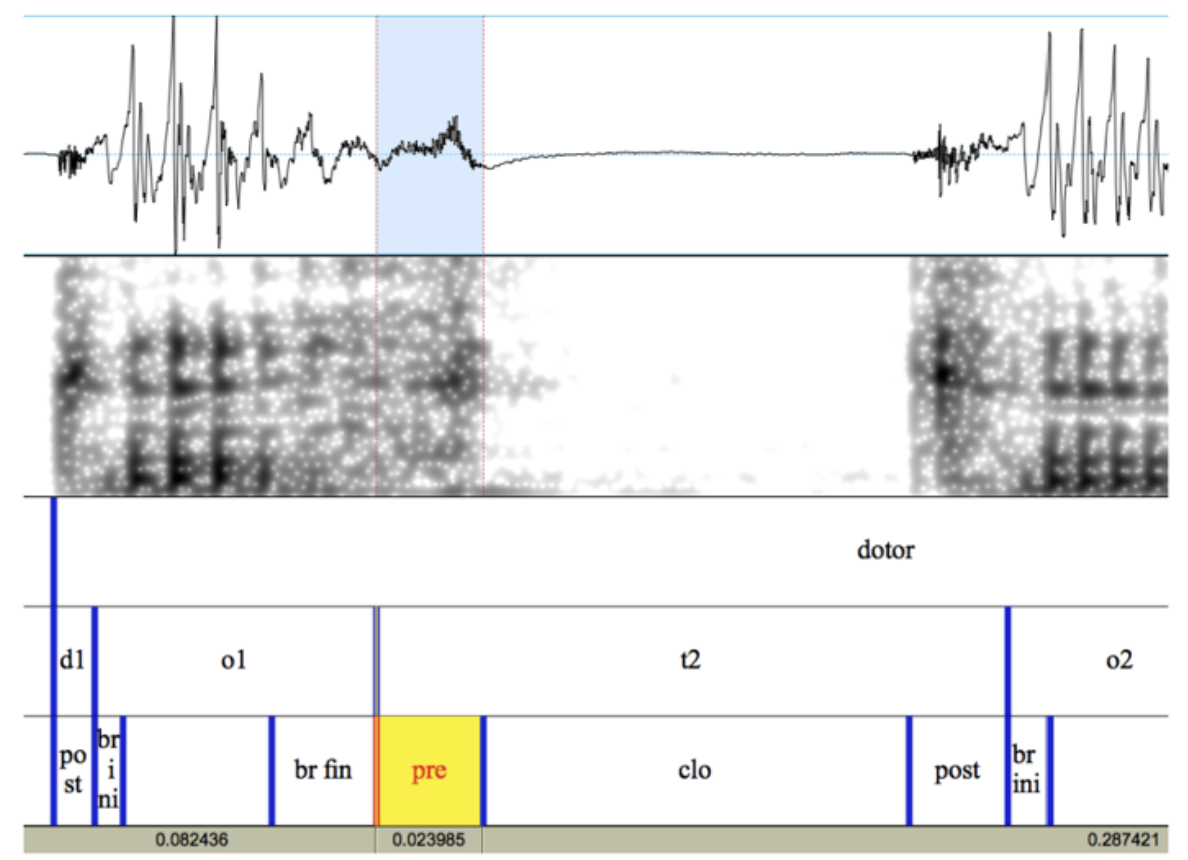

Figure 2: Pre-aspiration in the word dotor 'inside'. 'clo' = closure, 'post' = release, 'br ini' = breathiness caused by preceding release, 'br fin' = breathiness preceding voiceless pre-aspiration (or occurring without pre-aspiration at the end of the vowel).

Glottal friction is furthermore spectrally different from orally generated friction, especially when contrasted with the oral friction of /s/. In the context of /s/ then, the right boundary of pre-aspiration could be distinguished from the oral friction of the fricative itself as there was a clear separation of frequency regions associated with the highest intensity in the spectrogram.

Pre-aspiration is often accompanied by an interval of voiced breathiness, the annotation of which we describe in what follows.

\subsubsection{Breathiness}

Local breathiness can be defined as a phonatory setting during which the vocal folds vibrate and during which glottal friction is generated. As 
seen in Figure 2 (p. 41), the corresponding waveform is characterised by more quasi-sinusoidal properties, which often goes hand in hand with the presence of glottal friction across a wide range of frequencies. This also results in the attenuation of formants. The criteria for breathiness identification also follow those adopted in the studies mentioned above. Local breathiness was annotated at the end of vowels in vowel-obstruent sequences, but also following obstruents in obstruent-vowel sequences (see Figure 2 p. 41).

\subsubsection{Overall vowel breathiness}

Due to a fair amount of individual variation characteristic of breathiness, the manual annotation of the phenomenon proved rather challenging. For example, although more locally breathy intervals can often be seen, it is frequently the case that the whole vowel appears to be breathier in some consonantal contexts. For this reason, apart from the manual annotation of local breathiness, we also quantified breathiness in 5 subsequent intervals within the vocalic interval via the measure of Cepstral Peak Prominence (CPP) extracted using the VoiceSauce software (Shue 2010; Shue et al. 2011) in Matlab (2016). CPP was chosen since it has been described as the best perceptual correlate of breathiness (Fraile \& Godino-Llorente 2014; Hillenbrand et al. 1994, 776).

\subsubsection{Other relevant phonetic variation}

Mongolian segments present a degree of phonetic variation which was not taken into account in the present study, but which may have implications for the analysis of aspiration dissimilation. These instances of phonetic variation are linked to the fact that 1 . /g/ and /G/ can undergo spirantisation, and be occasionally devoiced; 2 . /l/ can be realised as a voiceless fricative; 3. vowels can undergo deletion and/or devoicing and, as a result, some plosives can have complex releases, which renders them unusable for direct comparisons with the duration of simple releases. Note that almost all these vowels are non-initial short vowels, which are analysed by Svantesson et al. (2005) as epenthetic vowels (cf. Section 3.3.2). Finally, 4. unexpected vocoids occur in some of the data: one speaker pronounced CVC as CVCə. These tokens were counted as disyllabic. We leave tackling this variation for future, more detailed analyses of the data. In the present analysis, /g/ and /G/ were treated as lenis stops and /3/ as a sonorant; CVC sequences in which the vowel was devoiced or deleted were excluded from the analysis. 


\subsubsection{Statistical analyses}

All statistical modelling was carried out using the lme4 package (Bates et al. 2014), the lmerTest package (Kuznetsova 2015), and the Effects package (Fox et al. 2017) in R using RStudio (R Core Team 2009-2015). In the list below, breathiness refers to local breathiness (see Section 2.3.3), i.e. the portion of the vowel showing an increasing presence of glottal friction due to the post- and/or pre-aspiration that follows and/or precedes. The dependent variables included in the analyses were thus the following.

1. release duration of $\mathrm{C}_{1}$ fortis plosives

2. post-aspiration duration of $\mathrm{C}_{1}$ fortis fricatives $(/ \mathrm{s} /)$

3. release duration of $\mathrm{C}_{2}$ fortis plosives

4. post-aspiration duration of $\mathrm{C}_{2}$ fortis fricatives $(/ \mathrm{s} /)$

5. post-aspiration frequency of $\mathrm{C}_{1} / \mathrm{s} /$

6. post-aspiration frequency of $\mathrm{C}_{2} / \mathrm{s} /$

7. pre-aspiration duration of $\mathrm{C}_{2}$ fortis plosives

8. pre-aspiration duration of $\mathrm{C}_{2}$ fortis fricatives $(/ \mathrm{s} /)$

9. pre-aspiration frequency of $\mathrm{C}_{2}$ fortis plosives

10. pre-aspiration frequency of $\mathrm{C}_{2}$ fortis fricatives (/s/)

11. breathiness duration of $\mathrm{C}_{2}$ fortis plosives

12. breathiness duration of $\mathrm{C}_{2}$ fortis fricatives (/s/)

13. breathiness frequency of $\mathrm{C}_{2}$ fortis plosives

14. breathiness frequency of $\mathrm{C}_{2}$ fortis fricatives (/s/)

15. breathiness duration of $\mathrm{C}_{1}$ fortis plosives

16. breathiness duration of $\mathrm{C}_{1}$ fortis fricatives (/s/)

17. breathiness frequency of $\mathrm{C}_{1}$ fortis plosives

18. breathiness frequency of $\mathrm{C}_{1}$ fortis fricatives $(/ \mathrm{s} /)$

19. overall breathiness of the vowel (CPP)

SPEAKER and WORD were always entered in the models as random effects. The relevant independent variables are fully specified in the Appendices. The independent factors of highest relevance to the research questions are mentioned in the Results section.

\section{Results}

In this section, we first report the phonetic implementation of the obstruents within our dataset (Section 3.1). Next, we present the analysis carried out in order to shed more light on whether there is indeed a gradient regressive aspiration dissimilation in Halh Mongolian (Section 3.2). We do so for fortis plosives (3.2.1) and /s/ (3.2.2), i.e. a fortis fricative, in 
order to see whether /s/ patterns with fortis plosives. We then proceed to the analyses targeting whether there is any evidence of progressive aspiration dissimilation in the data as well (Section 3.3). Finally, we explore whether vowel length affects any dissimilatory pattern in our data (Section 3.4).

\subsection{The phonetic implementation of obstruents in Halh}

\subsubsection{Fortis plosives}

Our inspection of the phonetic implementation of fortis plosives reveals some differences regarding previous reports available for Halh (e.g. Svantesson \& Karlsson 2012).

Firstly, release duration distinguishes the fortis and the lenis plosive series in our data, not only word-initially, but also word-medially, and it may also do so word-finally. This is in contradiction with Svantesson \& Karlsson's (2012) results: they found that the lenis-fortis contrast was primarily realised by pre-aspiration, the difference between lenis and fortis stops' VOT being non significant in intervocalic position. In addition, we find that lenis plosives show longer release duration word-finally than fortis plosives, although in this case the result is only approaching significance (see Table 6). ${ }^{13}$

\begin{tabular}{llcc}
\hline & Lenis & Fortis & Significant? \\
\hline Initial & $13 \mathrm{~ms}$ & $47 \mathrm{~ms}$ & Yes \\
Medial & $18 \mathrm{~ms}$ & $45 \mathrm{~ms}$ & Yes \\
Final & $80 \mathrm{~ms}$ & $45 \mathrm{~ms}$ & No \\
\hline
\end{tabular}

Table 6: Fortis-lenis plosive release duration (average) and contrast

Secondly, we find differences related to pre-aspiration as well. Whilst we corroborate that it is only found in the fortis series, we find that 'pre-

\footnotetext{
${ }^{13}$ We obtained $\mathrm{p}=0.0578$. This just misses the significance alpha level. It is suprising that word-final release duration for fortis plosives is in fact shorter than that of wordfinal lenis plosives. We are not able at the moment to explain this finding. Further research may confirm our impression that the two series are distinguished by the spectral properties of the release rather than by temporal properties. In any case, it does not affect our results for dissimilation (Section 3.2), since syllabic structure was taken into account in the statistical analysis (and no effect was found).
} 
aspiration' in Halh is realised as a combination of breathiness and voiceless glottal friction intervals. If we measure only pre-aspiration in the narrow sense, we find that the phenomenon applies less frequently in our dataset than as reported in Svantesson \& Karlsson (2012), with the rate of application of $42 \%$ medially and that of $25 \%$ finally. In terms of duration, pre-aspiration in the narrow sense reaches values of $18 \mathrm{~ms}$ for medial fortis stops in our data, and 13ms for final fortis stops (on average). However, if we merge local breathiness and pre-aspiration as defined here to form pre-aspiration in a broader sense (i.e. including both voiceless pre-aspiration and the local breathiness it induces), we reach results very comparable to those reported in Svantesson \& Karlsson (2012). Namely, pre-aspiration in the broad sense of the term applies in $99 \%$ of the word-medial cases and in $91 \%$ of the word-final cases. The average duration of broadly defined pre-aspiration is that of $43 \mathrm{~ms}$ wordmedially and $27 \mathrm{~ms}$ word-finally, which corresponds to the measurements reported in Svantesson \& Karlsson $(2012,456)$ : they find a pre-aspiration duration of $40 \mathrm{~ms}$ on average word-medially, and $24 \mathrm{~ms}$ on average wordfinally. Importantly, however, values of $0 \mathrm{~ms}$ have to be included for us to obtain comparable results, i.e. instances in which pre-aspiration does not apply. Once these are excluded, we reach the average duration of preaspiration of $52 \mathrm{~ms}$ word-medially and $46 \mathrm{~ms}$ word-finally.

Finally, one of the speakers (MN1) shows categorical absence of preaspiration. Whilst she differs from the other speakers in that she was raised in Southern Mongolia, the absence of pre-aspiration is still unexpected for this geographical background (Svantesson et al. 2005; Karlsson \& Svantesson 2012).

\subsubsection{Phonetic implementation of /s/}

According to Svantesson et al. $(2005,18)$, /s/ is post-aspirated wordinitially and word-medially in Halh Mongolian. Our data provide more precise information. /s/ is post-aspirated (in the narrow sense) in wordinitial position in $93 \%$ of the cases, with the average post-aspiration duration of $28 \mathrm{~ms}$. Word-medially, post-aspiration of /s/ reaches $42 \%$ of application rate. Medially, post-aspiration is shorter than initially (13ms). ${ }^{14}$ No post-aspiration was found in the final position. Vowel-initial breathi-

\footnotetext{
${ }^{14}$ When calculating the average duration, only cases where post-aspiration was found were included. This means that we did not include post-aspiration of $0 \mathrm{~ms}$ in the average calculation, in which case we would reach the value of $27 \mathrm{~ms}$ initially and $4 \mathrm{~ms}$ non-initially.
} 
ness induced by $\mathrm{C} 1 / \mathrm{s} /$, on the other hand, reaches the average duration of $16 \mathrm{~ms}$. When the two laryngeal components are combined, the result is the average duration of $44 \mathrm{~ms}$ for $\#\left[\mathrm{~s}^{\mathrm{h}}\right]$. Medially, voiceless $/ \mathrm{s} /$ postaspiration, with its average $13 \mathrm{~ms}$, is shorter than the local breathiness found in the post-/s/ vowel, with its $18 \mathrm{~ms}$. Combined, the two individual laryngeal components give us the average duration of $31 \mathrm{~ms}$.

\subsection{Is there regressive gradient dissimilation in Halh?}

\subsubsection{Fortis plosives}

We confirm the report that there is gradient regressive aspiration dissimilation in Halh Mongolian: the release duration of $\mathrm{C}_{1}$ fortis plosives $\left(/ \mathrm{p} /\right.$ and $/ \mathrm{t} /$ ) is affected by the type of $\mathrm{C}_{2}$ consonant (fortis plosive, lenis plosive, sonorant, fortis fricative), as shown in Figure 3. More specifically, the release duration of $\# C^{\mathrm{h}}$ is the shortest when $\mathrm{C}_{2}$ is an aspirated stop. The gradient dissimilatory effect holds for the combination of the voiced and the voiceless intervals of glottal friction (that is, post-aspiration in the broad sense). When we consider these two parts separately, we find a (slightly smaller) dissimilatory effect for post-aspiration in the narrow sense (cf. Figure 3 below), and no effect for the local breathiness induced by $\mathrm{C}_{1}$.

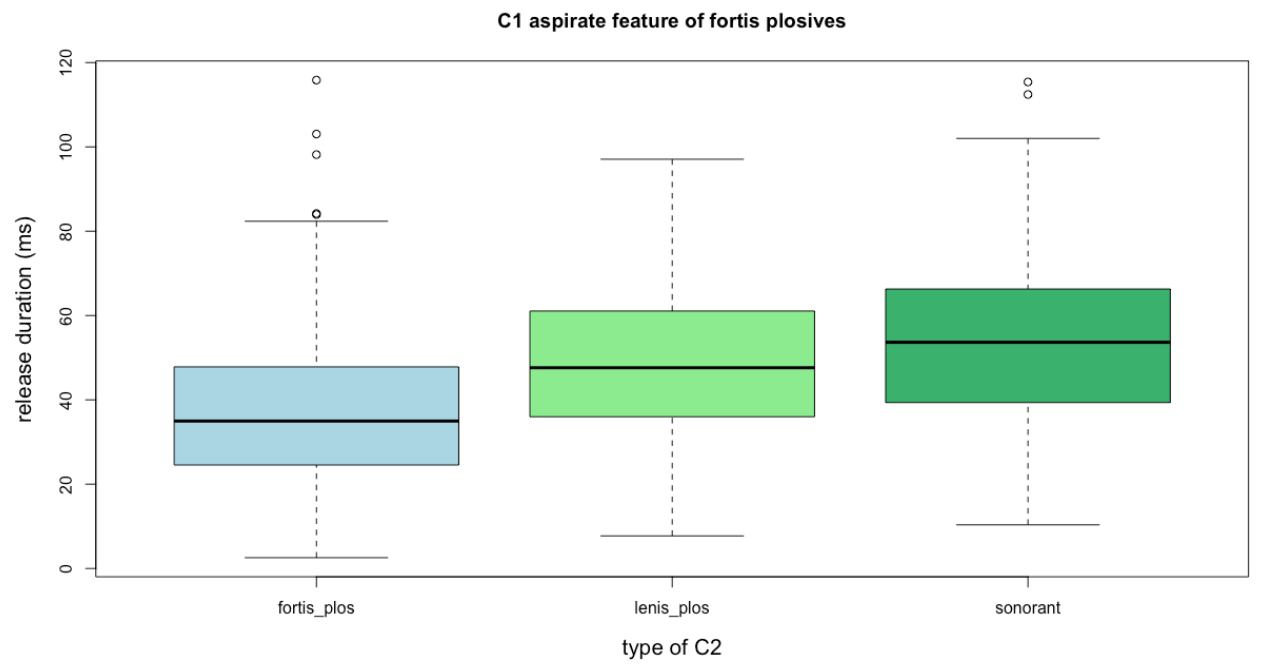

Figure 3: Effects of $\mathrm{C}_{2}$ type on $\mathrm{C}_{1}$ fortis plosive release duration

It should be noted that Speaker MN1, from Southern Mongolia, does participate in regressive dissimilation, although she does not pre-aspirate. 
Interestingly, visual inspection of Figure 3 (p. 46) suggests that lenis plosives trigger an intermediate degree of dissimilation: the duration of $\mathrm{C}_{1}$ post-aspiration is longer in TVD than in TVT, but shorter in TVD than in TVR. ${ }^{15}$

We did not find any significant interactions with the type of $\mathrm{C}_{2}$ and the other variables considered; this includes the overall syllabic structure (See Table A.8 in the Associated materials for the statistical details).

\section{$3.2 .2 / \mathrm{s} /$}

Regarding the phonetic implementation of word-initial /s/, the fricative is almost always post-aspirated, and no effects were therefore found on its rate of application (Associated materials, Table A.9). However, we present new data that enable us to investigate whether word-initial /s/ undergoes gradient regressive aspiration dissimilation, similarly to wordinitial fortis plosives. On the one hand, the average duration of postaspiration of word-initial /s/ is not affected by any of the factors considered (Associated materials, Table A.10). This holds for post-aspiration in the narrow sense, as well as for the combination of voiced and voiceless friction.

On the other hand, two individuals show qualitatively different results. As Figure 4 (p. 48) shows, speakers MN2 and MN4 display the shortest $C_{1}$ /s/ post-aspiration duration when $\mathrm{C}_{2}$ is a fortis plosive, followed by the category of lenis plosives with slightly higher values, followed by sonorants and /s/.

This result is interesting in several respects. Firstly, there seems to be individual variation related to whether /s/ post-aspiration also exhibits gradient regressive aspiration dissimilation. Secondly, it is only the speakers with longer post-aspiration that display the potential dissimilatory pattern. It may be the case that aspiration dissimilation can only apply once an aspirate feature (in a neutral sense of the word) reaches a certain durational threshold. Thirdly, for six of the speakers, /s/, a fortis obstruent, does not pattern with the plosive fortis obstruents in being affected by the type of $\mathrm{C}_{2}$.

\footnotetext{
${ }^{15}$ The difference between the levels was compared with /s/ as the baseline. Comparisons between $\mathrm{C}_{2}$ fortis plosives and lenis plosives doesn't reveal a significant difference in their effect on $\mathrm{C}_{1}$ post-aspiration. However, there is a significant difference between fortis plosives and sonorants $(\mathrm{p}<0.05)$. For the analysis with $/ \mathrm{s} / \mathrm{as}$ the baseline, see Table A.15 in the Associated materials.
} 
$\mathrm{C} 1 / \mathrm{s} /$ post-aspiration by C2 type - individual differences

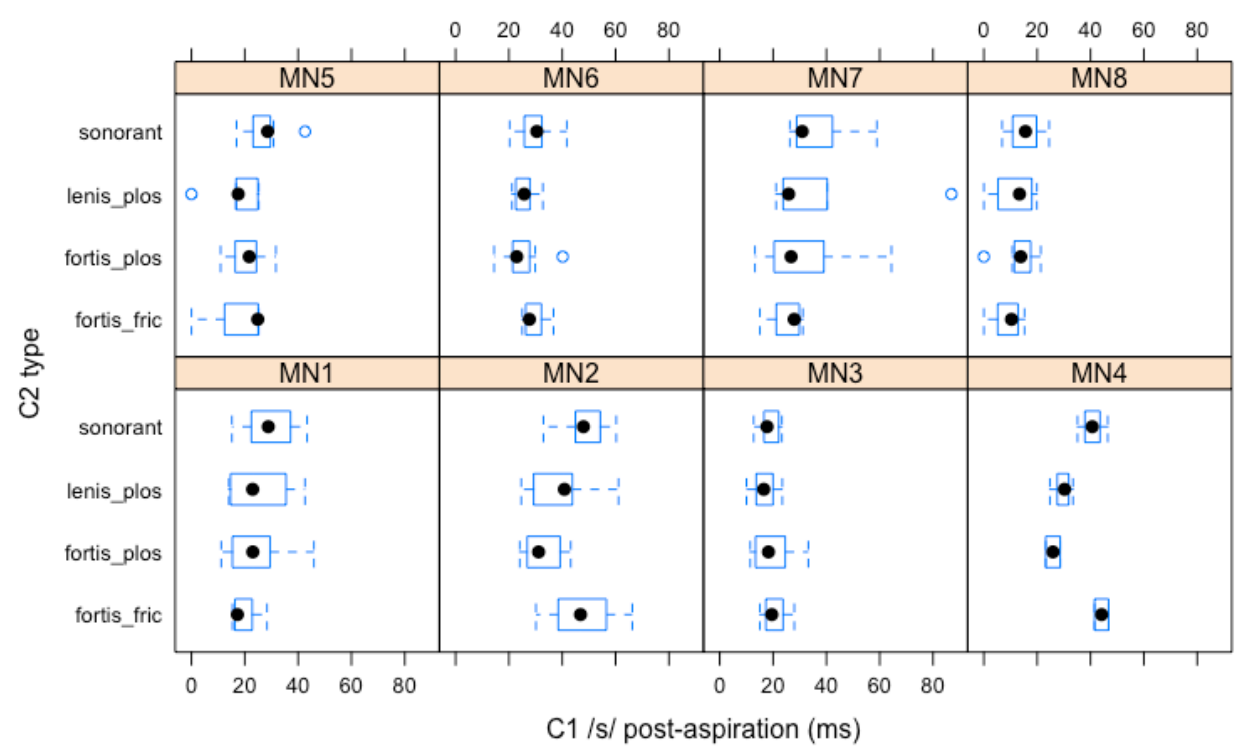

Figure 4: Effects of $C_{2}$ type on $C_{1}$ /s/ post-aspiration duration by individual (ms)

If we turn now to $\mathrm{C}_{2} / \mathrm{s} /$, we find that intervocalic and word-final /s/ trigger a degree of dissimilation (Figure 5 p. 49). On visual inspection, $C_{1}$ shows a slight release duration reduction with $\mathrm{C}_{2} / \mathrm{s} /$ in comparison to $\mathrm{C}_{2}$ sonorants. However, /s/ patterns together with lenis plosives in being associated with longer $\mathrm{C}_{1}$ fortis plosive release duration than fortis plosives. The difference between fortis plosives and /s/ as triggers of gradient dissimilation is nonetheless not supported by the statistical analyses (although it approaches significance, with $\mathrm{p}=0.067$; $\mathrm{cf}$. Associated materials, Table A.8).

For a direct comparison with the previous studies of Halh Mongolian, we also report dissimilation related results for the words tatax 'to pull', tos 'fat', tag 'completely', and tal 'steppe' and contrast them with previous findings. As Table 7 (p. 49) shows, our data replicate partially the findings reported by Svantesson \& Karlsson (2012). It is indeed the case that $\mathrm{C}_{2}$ sonorants are associated with the longest release duration of $\mathrm{C}_{1}$ fortis plosives; however, it is not the case that $\mathrm{C}_{2} / \mathrm{s} /$ would pattern with $\mathrm{C}_{2} / \mathrm{t} /$; instead, /s/ patterns with lenis plosives. 


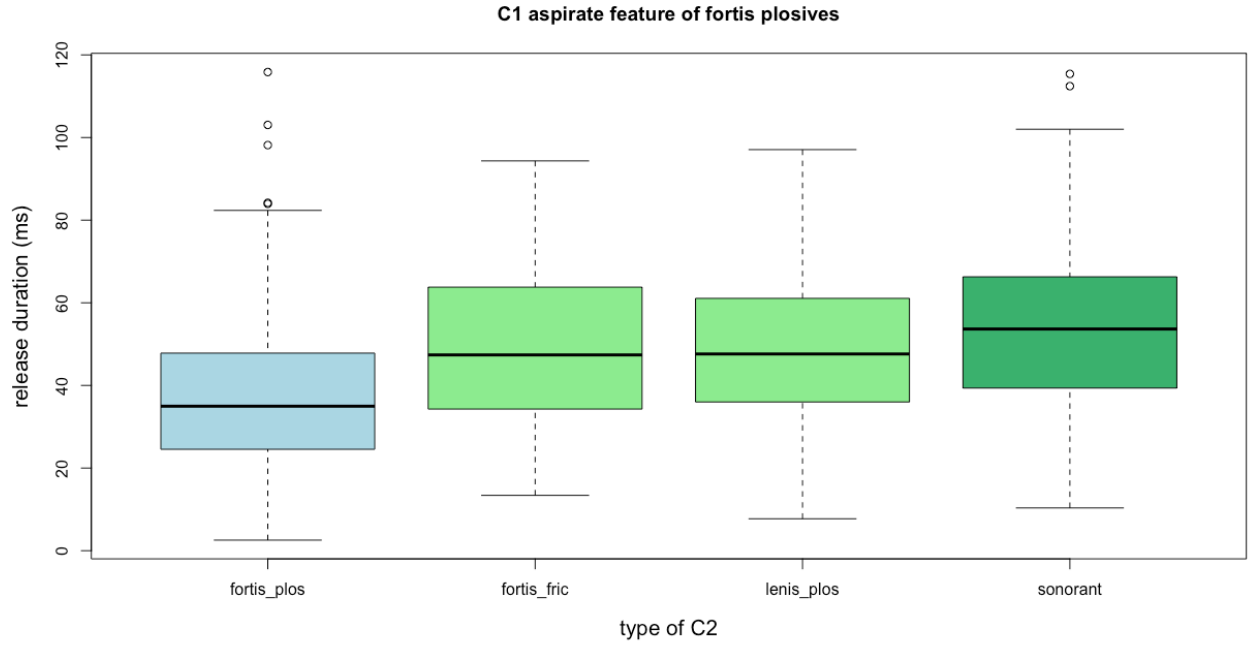

Figure 5: Effects of $C_{2}$ type on $C_{1}$ fortis plosive release duration, including /s/ in $C_{2}$

\begin{tabular}{lcc}
\hline & $\begin{array}{c}\text { S\&K 2012 } \\
\text { (1 speaker) }\end{array}$ & $\begin{array}{c}\text { Our data } \\
\text { (8 speakers) }\end{array}$ \\
\hline$\left[\mathrm{t}^{\mathrm{h}} \mathrm{a}^{\mathrm{h}}\right.$ tax $]$ & $50 \mathrm{~ms}$ & $34 \mathrm{~ms}$ \\
{$\left[\mathrm{t}^{\mathrm{h}}\right.$ os $]$} & $49 \mathrm{~ms}$ & $52 \mathrm{~ms}$ \\
{$\left[\mathrm{t}^{\mathrm{h}} \mathrm{ag}\right]$} & - & $53 \mathrm{~ms}$ \\
{$\left[\mathrm{t}^{\mathrm{h}} \mathrm{aj}\right]$} & $72 \mathrm{~ms}$ & $63 \mathrm{~ms}$ \\
\hline
\end{tabular}

Table 7: Comparison between previous reports and our results: $\mathrm{C}_{1}$ release duration in different contexts

\subsection{Is there progressive gradient dissimilation in Halh?}

\subsubsection{Individual variation in pre-aspiration duration}

Firstly, none of the statistical analyses support presence of progressive gradient dissimilation in the data. ${ }^{16}$ Nevertheless, $\mathrm{C}_{2}$ pre-aspiration unlike $\mathrm{C}_{2}$ release duration - does show individual differences. As Figure 6 (p. 50) demonstrates, two speakers (MN4 and MN7) are qualitatively different from the others in that their pre-aspiration duration does seem to be affected by the type of $\mathrm{C}_{1}$ in the manner expected in aspiration dissimilation. This may possibly be extended to speaker MN8 as well.

\footnotetext{
${ }^{16}$ See Tables A.11-A.21 in the Associated materials.
} 


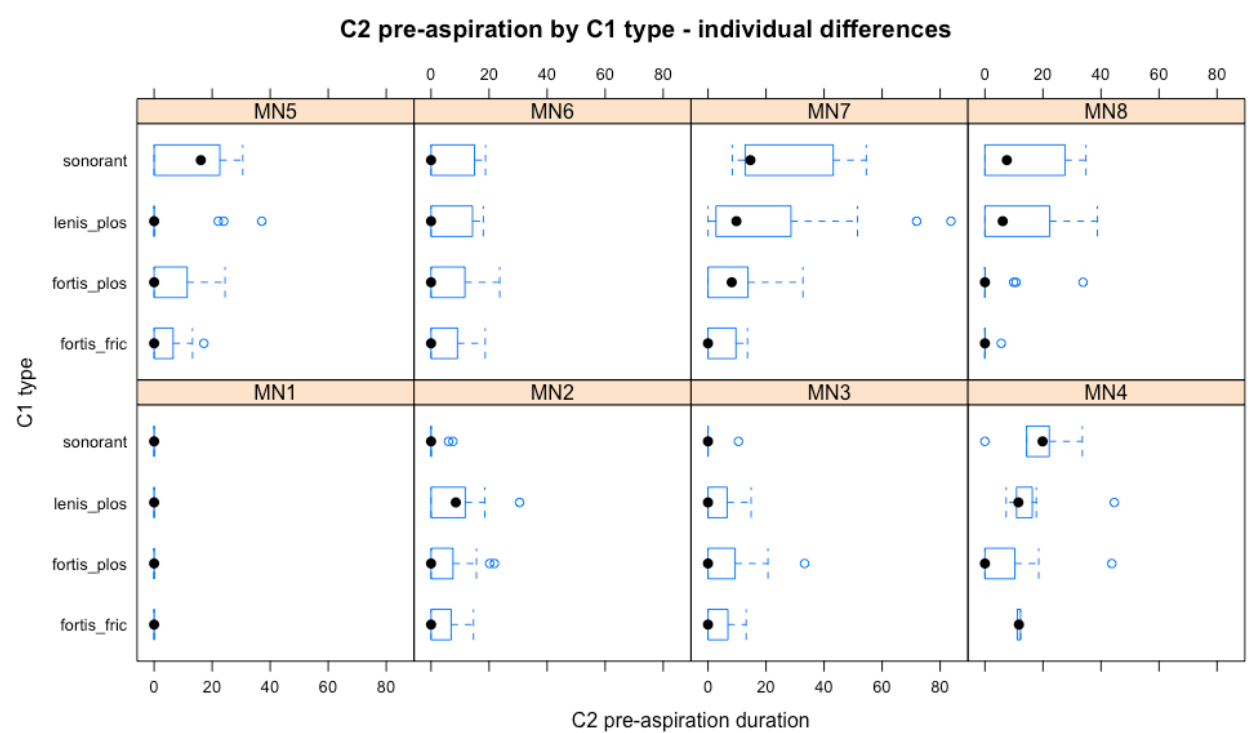

Figure 6: Effects of $\mathrm{C}_{1}$ type on $\mathrm{C}_{2}$ fortis plosive pre-aspiration duration by individual

\subsubsection{Breathiness measurements}

At this point, it is also noteworthy to report the results obtained for the amount of breathiness in the intervening vowel, as quantified by CPP. Statistical analyses do not confirm that the intervening vowel is less breathy (associated with higher CPP values) in the dissimilating contexts, nor is it breathier. ${ }^{17}$ In other words, there are many completely breathy vowels in our corpus, with various degrees of noisiness. However, this breathiness is not linked to the $\mathrm{C}^{\mathrm{h}} \mathrm{VC}$ context: it cannot be interpreted as a coarticulatory effect between aspirated consonants (including fortis stops and /s/). On the other hand, we find very few completely voiceless vowels (in the first syllable; see Section 2.3.5). This confirms that speakers do not produce one long spread glottis gesture across $\mathrm{C}^{\mathrm{h}} \mathrm{VC}$ contexts. The same result was found in Aberystwyth English (Jatteau \& Hejná 2016). Finally,

\footnotetext{
${ }^{17}$ A number of models were run to look into the effects of $C_{1}$ and $C_{2}$ type on the breathiness of the intervening vowel. For these purposes, CPP measures were taken within five chunks/intervals of the vocalic interval, which was simply divided by five, i.e. each interval represents $20 \%$ of the vocalic interval. For the effects of $C_{1}$ on the breathiness of the vowel, the CPP values of the fourth and the fifth intervals were entered in the models as dependent variables. For the effects of $\mathrm{C}_{2}$ on the breathiness of the vowel, the CPP values of the first and the second intervals were entered in the models as dependent variables. This was done separately for fortis plosives and /s/.
} 
we didn't find any significant decrease in noisiness in any of the five slices of the vowels. This means that the gradient dissimilation pattern does not trigger a decrease in noisiness in the breathy interval induced by the aspiration features: it only affects the duration of the post-aspiration feature.

\subsection{Does vowel length affect any dissimilatory patterns in Halh?}

As mentioned, in Chahar aspiration dissimilation is blocked in the context of an intervening phonologically long vowel. These effects were not found for the gradient dissimilation pattern in Halh Mongolian, manifested in the release duration of $\mathrm{C}_{1}$ fortis plosives (or in $\mathrm{C}_{2}$ ). On the whole, this means that both long and short vowels trigger gradient regressive dissimilation as manifested in $\mathrm{C}_{1}$ fortis plosives, and neither long nor short vowels trigger dissimilation as manifested in $\mathrm{C}_{2}$ fortis plosives. Vowel length is nevertheless important in that it is associated with less frequent and shorter pre-aspiration. ${ }^{18}$ This is in accordance with cross-linguistic findings on pre-aspiration (Hejná 2015, chap. 3-4). Note that Karlsson \& Svantesson $(2012,13)$ find a similar effect in Baarin (Eastern Mongolian).

\subsection{Summary of the results}

To summarise, our results confirm the existence of a gradient dissimilatory pattern in Halh Mongolian, as reported by Svantesson et al. (2005); Svantesson \& Karlsson (2012). We report that this effect does not depend on the syllabic structure of the word. The sets of triggers and undergoers is different from the ones reported in the literature. First, we find that /s/ undergoes a degree of reduction in $\mathrm{s}_{-} \mathrm{C}^{\mathrm{h}}$ contexts in the speech of two, maybe three speakers. These speakers display the longest duration of \#spost-aspiration on average. Second, we find that only aspirated stops are able to trigger the dissimilation: /s/ does not. Our data noteworthily differ in this respect from Svantesson and his colleagues. Interestingly, we find a gradient scale between the different types of consonants: $\mathrm{T}>\mathrm{D}$, $\mathrm{s}>\mathrm{R}$, where ' $>$ ' means 'trigger a greater reduction of $\mathrm{C}_{1}$ post-aspiration than'. In this scale, /s/ patterns with lenis stops rather than fortis stops in triggering an intermediate degree of $\mathrm{C}_{1}$ post-aspiration reduction.

\footnotetext{
18 The statistical models presented in the Associated materials never contain an interaction between type of consonant and vowel length; this is because the models lacking this interaction better accounted for the variation found in the dataset and because the interaction was never found to be significant.
} 
As regards progressive dissimilation, our data does not present any global effect, but two speakers seem to show progressive dissimilation as well, that is, a bidirectional gradient dissimilatory effect.

Concerning the intervening vowel, we do not find any specific rise or decrease in the degree of breathiness of vowels surrounded by aspirated stops or /s/: the reduction does not affect the degree of breathiness of the intervening vowel. Finally, the phonological length of the intervening vowel does not affect the dissimilatory process: the post-aspiration of $\mathrm{C}_{1}$ is reduced both in $\mathrm{C}^{\mathrm{h}} \mathrm{VC}^{\mathrm{h}}$ and $\mathrm{C}^{\mathrm{h}} \mathrm{V}: \mathrm{C}^{\mathrm{h}}$.

\section{Discussion}

We can now come back to our research questions in (7), repeated here for convenience.

(9) 1. Is gradient dissimilation indeed attested in Halh, as described by Svantesson et al. (2005); Svantesson \& Karlsson (2012)?

- Is it regular across speakers? Is it regular across different word structures (mono- vs. polysyllables)? Do we find the same set of triggers and undergoers?

2. Could it show the phonetic precursor of the Chahar dissimilation pattern?

- Is it sensitive to the length of the intervening vowel?

3. Could it show the phonetic precursor of both the Chahar and Monguor dissimilatory patterns?

- $\quad$ Is it both regressive and progressive?

\subsection{Gradient dissimilation in Halh}

Our results confirm the existence of a pattern of gradient dissimilation in Halh Mongolian, as described by Svantesson et al. (2005). We are now able to describe the pattern more precisely (Section 4.1.1). Nonetheless, we report partly different results regarding the role of /s/ (Section 4.1.2). These findings shed an interesting light on the question of the behaviour of fricatives in aspiration dissimilations.

\subsubsection{Fortis stops show gradient dissimilation}

Our data confirm that there is a regressive, gradient dissimilatory effect in Halh Mongolian: the post-aspiration feature of $\mathrm{C}_{1}$ in $\mathrm{C}^{\mathrm{h}} \mathrm{VC}$ is reduced when the second consonant of the word is an aspirated stop. Gradient 
dissimilation in our data is triggered, and undergone, by aspirated stops. We have shown that it does not depend on the prosodic structure of the word: the results in CVC words are comparable to the results in polysyllabic words.

Interestingly, our findings suggest that the dissimilatory effect does not categorically depend on the laryngeal specification of $\mathrm{C}_{2}$ : lenis stops trigger a degree of dissimilation, smaller than fortis stops, but bigger than sonorants. This effect can be illustrated by the following triplet.

$$
\begin{aligned}
& \text { VOT duration of } \mathrm{C}_{1} \text { depending on the type of } \mathrm{C}_{2} \\
& \begin{array}{lll}
\text { a. } & {\left[\mathrm{t}^{\mathrm{h}} \mathrm{a}\right. \text { t }} & 43 \mathrm{~ms} \\
\text { b. } & {\left[\mathrm{t}^{\mathrm{h}} \mathrm{ag}\right]} & 53 \mathrm{~ms} \\
\text { c. } & {\left[\mathrm{t}^{\mathrm{h}} \mathrm{a}\right]} & 63 \mathrm{~ms}
\end{array}
\end{aligned}
$$

This trend would need to be confirmed in a bigger corpus. If it turned out to be supported, a possible interpretation would be that the dissimilatory effect depends on the $\mathrm{C}_{2}{ }^{\text {'s VOT: }}{ }^{19}$ fortis stops have the longest VOT, lenis stops have an intermediate VOT, and sonorants do not have any. This hypothesis is compatible with the results we find for $/ \mathrm{s} /$.

\subsubsection{The role of $/ \mathrm{s} /$}

A major difference between our study and Svantesson et al.'s (2005; 2012) lies in the role of /s/: in our data, the fricative may undergo, but not trigger gradient dissimilation. This result is problematic in the context of Mongolian, but it may shed light on the behaviour of /s/ as an aspirated consonant in dissimilatory patterns, in Mongolian and beyond.

There is ample evidence in Mongolian that /s/ patterns as a natural class with aspirated consonants. In particular, it was involved in the two complete dissimilatory patterns, in Chahar and Monguor (see section 1.3). In both cases, /s/ differs from aspirated stops in that it can trigger, but not undergo aspiration dissimilation. It should be recalled that Mongolian has only one series of fricatives (there is no laryngeal contrast for this series). Even if a phonetic reduction of the aspiration applied to /s/, there is no other fricative phoneme it can merge with. In Monguor, /s/ also triggered (but did not undergo) aspiration metathesis (see Section 1.3). These diachronic patterns are in accordance with the contemporary phonetic realisation of /s/ in Halh: it is realised with post-aspiration

\footnotetext{
${ }^{19}$ In the case of aspirated stops, this parameter may include the pre-occlusion part of the feature in addition to the VOT.
} 
in word-initial position (with an average VOT of 28ms) as well as in intervocalic position, although with shorter duration and less regularly so (with an average VOT of $13 \mathrm{~ms}$; see Section 3.1.2). Mongolian is then a good test case for the idea, defended in particular by Vaux (1998), that voiceless fricatives are by default [+spread glottis] segments. Interestingly, however, Mongolian stands out as an exception within the typology of aspiration dissimilation: cross-linguistically, and contra Vaux's 1998 predictions, /s/ is very rarely involved in this process. ${ }^{20}$ Could it be then that only post-aspirated fricatives can be involved in aspiration dissimilation?

Our results are consistent with this hypothesis. In our data, Halh /s/ shows the opposite behaviour of Chahar and Monguor /s/: when it is word-initial, it may undergo gradient dissimilation in some speakers, but when it is word-medial or final, it does not trigger dissimilation like aspirated stops. This behaviour may be understood if gradient dissimilation correlates with the VOT duration of the consonants.

On the one hand, /s/ does trigger a degree of regressive dissimilation, but only a small one: the trend is only marginally significant, most likely due to the size of our dataset. Most importantly, it patterns with lenis stops rather than aspirated stops. This finding is in contradiction with Svantesson et al.'s results (cf. Section 1.2). This is shown in (11), where we add a $\mathrm{C}^{\mathrm{h}}$ Vs word to the triplet presented above in (10).

$$
\begin{aligned}
& \text { VOT duration of } \mathrm{C}_{1} \text { depending on the type of } \mathrm{C}_{2} \\
& \begin{array}{lll}
\text { a. } & {\left[\mathrm{t}^{\mathrm{h}} \mathrm{a}\right.} & 43 \mathrm{~ms} \\
\text { b. } & {\left[\mathrm{t}^{\mathrm{h}} \mathrm{as}\right]} & 54 \mathrm{~ms} \\
& {\left[\mathrm{t}^{\mathrm{h}} \mathrm{ag}\right]} & 53 \mathrm{~ms} \\
\text { c. } & {\left[\mathrm{t}^{\mathrm{h}} \mathrm{ab}\right]} & 63 \mathrm{~ms}
\end{array}
\end{aligned}
$$

Statistical analyses showed that the effect of /s/ was different from both sonorants and aspirated stops. ${ }^{21}$ But why, then, would /s/ behave like a lenis stop? It needs to be remembered that /s/ post-aspiration is

\footnotetext{
20 The other cases we know of are Ofo, where $/ \mathrm{s}^{\mathrm{h}} /$ is contrastively post-aspirated (de Reuse 1981), and Harauthi, which has only one coronal fricative (Allen 1957). In this language, which displays a co-occurrence restriction on aspiration and a 'leftness effect', the sequence $s \ldots C^{h}$ is prohibited, but $C^{h} \ldots s$ is possible. This asymmetry is very similar to the Monguor case, and could result from a progressive dissimilation pattern which /s/ triggered but did not undergo (cf. fn. 9). The generalisation is that /s/ acts as an aspirated consonant in the position of trigger, but not in the position of target.

${ }^{21}$ In the latter case, the difference between the dissimilating effect of $C_{2} / s /$ and $C_{2}$ aspirated stops is only approaching significance $(p=0.067)$.
} 
variable in medial position, applying in $42 \%$ of the cases. This may account for the difference with aspirated stops. Another possible factor is the duration of the VOT. We have shown that lenis stops in Halh have a rather long VOT: 18ms on average. This is comparable to intervocalic /s/, which has a VOT of $13 \mathrm{~ms}$ on average. It may then be that gradient dissimilation in Halh is directly linked to the duration of the consonants' VOT.

On the other hand, we find that /s/ can undergo regressive dissimilation for some individuals: for three speakers, the VOT duration of wordinitial $\left[\mathrm{s}^{\mathrm{h}}\right]$ is reduced in $\mathrm{sVC}^{\mathrm{h}}$ as opposed to $\mathrm{sVC}$. These speakers are precisely the ones with the longest post-aspiration for word-initial /s/. It seems, then, that gradient dissimilation is not only triggered, but also undergone, by segments with especially long VOT.

To summarise, /s/ can behave like aspirated stops in initial position, where it has a long VOT, but it behaves like lenis stops in intervocalic position, where its VOT is shorter. This interpretation is however tentative. 'VOT' in stops covers both release duration and post-aspiration proper, i.e. it does not enable us to distinguish whether a plosive is genuinely postaspirated (that is, pronounced with a period of glottal friction). Ideally then, we should quantify the presence of aspiration in the fortis plosives (something that mere release duration, and VOT, does not allow us to do reliably). In addition, it may be the case that the noisiness of aspiration participates in a trade-off relationship with duration (e.g. the noisier the post-aspiration, the shorter it can be). Furthermore, since the effects we are dealing with are rather small, the dataset needs to be enlarged with more speakers.

Nonetheless, if it turns out that the duration of the VOT is the most important factor in triggering and undergoing gradient dissimilation, and if gradient dissimilation is the phonetic precursor of lexically regular cases of (completed) dissimilation, we may be able to explain why /s/ is crosslinguistically inactive in this type of patterns. The phonetic factor relevant for aspiration dissimilation would not be the spread glottis gesture associated with the oral release of /s/, but rather with the post-aspiration which applies in a few languages, i.e. a predominantly laryngeal component of the fricative. ${ }^{22}$

This hypothesis predicts that other segments with similar VOT duration in Halh should behave like /s/. To investigate this question, further

\footnotetext{
${ }^{22}$ We do realise that oral fricatives always include a glottal gesture as well; however, the important difference between $/ \mathrm{s} /$ and $/ \mathrm{h} /$ is that the latter is associated with friction generated predominantly in the larynx, as opposed to the former.
} 
analyses will need to look at the other voiceless fricatives in the language: $/ \mathrm{J} /$, and voiceless occurrences of $/ \mathrm{l} /$, fricativized /g/ and /G/.

\subsection{Could gradient dissimilation be the precursor of the Chahar pat- tern?}

The analysis of our data globally suggests that Halh may represent the phonetic precursor of the dissimilation which happened in Chahar and other dialects of Mongolian: we do find a pattern of dissimilation, and it is regressive. However, two discrepancies appear between the two patterns: Halh gradient dissimilation is not triggered by /s/, and it holds over long vowels.

The first point has been discussed in section 4.1.2. It is problematic from a diachronic point of view: why would Chahar have changed $\left[\mathrm{t}^{\mathrm{h}} \mathrm{Js}\right]$ to [tos] if /s / did not trigger any gradient dissimilatory effect? The simplest assumption, to save our diachronic hypothesis, would be that ProtoMongolian had a more aspirated /s/ than Halh: a longer VOT may have triggered a more important dissimilatory effect. We do not however have any evidence for the phonetic realisation of Proto-Mongolian *s.

Regarding /s/ as an undergoer, we have shown that some Halh speakers show a dissimilatory effect of /s/ post-aspiration duration in $\mathrm{sVC}^{\mathrm{h}}$. It could be, then, that /s/ did undergo dissimilation in Chahar too: $\left[\mathrm{s}^{\mathrm{h}}\right]$ may have been reduced to [s]. The effect would only be visible in phonetic analyses, since the reduction of $\left[\mathrm{s}^{\mathrm{h}}\right]$ to $[\mathrm{s}]$ does not correspond to a phonemic neutralisation (as it does for $\left[\mathrm{t}^{\mathrm{h}}\right]>[\mathrm{t}]$ ). However, we do not have any information on the realisation of /s/ in Chahar.

The second difference between our Halh results and the Chahar pattern may also not be a problem for our diachronic hypothesis. In our Halh data, the phonological length of the vowel does not have any significant impact on aspiration dissimilation: the VOT of word-initial $/ \mathrm{t}^{\mathrm{h}} /$ is reduced both in [ $\mathrm{t}^{\mathrm{h}} \mathrm{a}^{\mathrm{h}} \mathrm{t}^{\mathrm{h}} \mathrm{ax}$ ] ('to pull') and [ $\left.\mathrm{t}^{\mathrm{h}} \mathrm{a}:{ }^{\mathrm{h}} \mathrm{t}^{\mathrm{h}} \varepsilon\right]$ ('pleasant'). This is not consistent with the Chahar dissimilation, which occurred over single vowels, as in ${ }^{*} t^{h} a t^{h} a$, but not over complex rhymes, as in ${ }^{*} k^{h} a u t{ }^{h}$ in (see section 1.3.1). Nevertheless, this mismatch is not sufficient to dismiss our diachronic hypothesis. A first explanation would be that Halh innovated the gradient dissimilation in $\mathrm{C}^{\mathrm{h}} \mathrm{V}: \mathrm{C}^{\mathrm{h}}$. Alternatively, it could be that the distinction between $\mathrm{C}^{\mathrm{h}} \mathrm{VC}^{\mathrm{h}}$ and $\mathrm{C}^{\mathrm{h}} \mathrm{V}: \mathrm{C}^{\mathrm{h}}$ arose at later stages of the change. In particular, if gradient dissimilation is the phonetic precursor of complete dissimilation, we need to assume that gradient reduction of the VOT underwent a phase of 'enhancement'. To be enhanced, a pattern needs to be perceived. We may then hypothesize that the gradient reduction of $\mathrm{C}_{1}$ 
VOT was more perceptible in $\mathrm{C}^{\mathrm{h}} \mathrm{VC}^{\mathrm{h}}$ than in $\mathrm{C}^{\mathrm{h}} \mathrm{V}: \mathrm{C}^{\mathrm{h}}$, that is, more likely to be exploited by the listener and enhanced. A related hypothesis is that gradient dissimilation would be more 'useful' in $\mathrm{C}^{\mathrm{h}} \mathrm{VC}^{\mathrm{h}}$ than in $\mathrm{C}^{\mathrm{h}} \mathrm{V}: \mathrm{C}^{\mathrm{h}}$. In $\mathrm{C}^{\mathrm{h}} \mathrm{VC}^{\mathrm{h}}$, the quality of the vowel is likely to be jeopardized by the surrounding aspirating features. ${ }^{23}$ This assumption is especially plausible in preaspirating languages, where both the beginning and the end of the vowel are affected by aspiration (as in $\left[\mathrm{t}^{\mathrm{h}} \mathrm{a}^{\mathrm{h}} \mathrm{t}\right]$ ). Enhancing the reduction of $\mathrm{C}_{1}$ VOT would then help perceive the quality of short vowels in $\mathrm{C}^{\mathrm{h}} \mathrm{VC}$. On the other hand, the quality of $\mathrm{V}:$ in $\mathrm{C}^{\mathrm{h}} \mathrm{V}: \mathrm{C}^{\mathrm{h}}$ should be easier to perceive: the vowel is longer, and pre-aspiration is shorter after long vowels. There would be then less pressure to dissimilate in the case of a long vowel.

In sum, the differences we find between the synchronic, gradient dissimilation in Halh and the diachronic dissimilation in Chahar do not suffice to discard our diachronic hypothesis: different diachronic scenarios may account for the behaviour of /s/ and the role of long vowels. In the latter case, these scenarios may be put to test in perceptual experiments. We plan to investigate this question in more detail in the future.

\subsection{Could gradient dissimilation be the precursor of both Chahar and Monguor dissimilations?}

Finally, Mongolian is exceptional in that the same language family presents dissimilatory patterns in opposite directions: regressive in Chahar and related dialects, progressive in Monguor. Could gradient dissimilation be the phonetic precursor of both processes? Our results do not allow a categorical answer to this question. On the one hand, we do not find any significant duration reduction of the pre-aspiration feature in $\mathrm{C}^{\mathrm{h}} \mathrm{V}^{\mathrm{h}} \mathrm{C}$, nor any significant effect on the degree of breathiness induced by the aspirated stops. On the other hand, visual inspection suggests that progressive dissimilation may depend on individual variation: two, maybe three speakers present a reduction effect of $\mathrm{C}_{2}$ pre-aspiration in $\mathrm{C}^{\mathrm{h}} \mathrm{VC}^{\mathrm{h}}$. This is very interesting, because it shows that the same individual can be doing both regressive and progressive gradient dissimilation. Such a bidirectional process is then a good candidate for the reconstruction of aspiration patterns in Old Mongolian, since it may explain why different branches underwent dissimilation in opposite directions.

These results also allow for a preliminary comparison between gradient dissimilation patterns. Contrary to what we find in Halh, the pre-

\footnotetext{
${ }^{23}$ For example, Lotto et al. (1997) show that the degree of breathiness of the vowel affects the vowel height perceived by the listener.
} 
aspiration feature of $\mathrm{C}_{2}$ in Aberystwyth English is significantly reduced in dissimilatory contexts (Jatteau \& Hejná 2016). However, we also find that pre-aspiration is implemented differently in the two languages: preaspiration in the broader sense is most frequently realised as a combination of a breathy interval and a period of voiceless friction in Aberystwyth English, while it is local breathiness rather than voiceless glottal friction that is primarily associated with the fortis plosives in Halh Mongolian. This comparison suggests that the implementation of gradient dissimilation may correlate with the implementation of the aspiration feature itself. We leave this question open for further research.

\section{Conclusion and directions for further research}

To conclude, our results globally support the hypothesis that gradient dissimilation could represent the phonetic precursor of lexically regular cases of dissimilation. Within the Mongolic family, Mongolian Halh may represent the incipient variation which evolved into the regressive pattern of Chahar. On the other hand, we have shown that gradient dissimilation could be bidirectional in some speakers; such a process may be proposed as a common precursor to both regressive and progressive patterns of dissimilation.

In both cases, the main problem is the behaviour of /s/. Contrary to Svantesson et al.'s $(2005 ; 2012)$ results, and to the predictions of our diachronic hypothesis, /s/ in our data does not pattern with fortis stops, but with lenis stops: it triggers an intermediate degree of dissimilation. We were able to report that /s/ may also undergo a gradient reduction of its post-aspiration feature in some speakers. In the present state of our knowledge, a possible interpretation would be that gradient dissimilation directly depends on VOT duration. It may help understand why /s / is rarely involved cross-linguistically in aspiration dissimilation: (gradient) dissimilation might affect only post-aspirated $\left[\mathrm{s}^{\mathrm{h}}\right]$, such as the Mongolian one, which is typologically rare. Further analyses will be required to confirm these trends.

In the end, our study suggests that Hoenigswald's (1964) prediction, presented in the epigraph of this paper, may well become true: some 
cases of dissimilation could be, after all, genuine instances of Neogrammarian change.

\section{Comments invited}

PiHPh relies on post-publication review of the papers that it publishes. If you have any comments on this piece, please add them to its comments site. You are encouraged to consult this site after reading the paper, as there may be comments from other readers there, and replies from the author. This paper's site is here:

https://doi.org/10.2218/pihph.3.2018.2821

\section{Acknowledgements}

We are very grateful to Raphaël Blanchier and Bolormaa Gord for their invaluable help with elaborating the word-list and contacting the participants.

\section{Author contact details}

\section{Adèle Jatteau}

Université Paris 8 \& CNRS

59-61 rue Pouchet

75017 Paris

France

a.jatteau@gmail.com

Michaela Hejná

Aarhus University

Jens Chr. Skous Vej 4

Aarhus C, 8000

Denmark

misa.hejna@cc.au.dk 


\section{Associated materials}

\section{Wordlist}

In the following table, the forms given are transliterations from the Cyrillic alphabet.

\begin{tabular}{lccc}
\hline & /a/ & /Ј/ & /כ:/ \\
\hline TVT & pap, tat & tot $^{\prime}$ & toot \\
TVD & pad, tag & tog & NA \\
TVR & pal, tal & tom & NA \\
TVs & tas & tos & toos \\
\hline
\end{tabular}

Table A.1: $\mathrm{C}_{1}$ fortis plosive in monosyllables

As we can see, contrasts between /a/ and /a:/ were not possible for monosyllabic words. In addition, the possibility of comparisons between / $\mathrm{J} /$ and $/ \mathrm{o}$ / and their interactions with consonantal type was limited only to TVT and TVs contexts. All efforts were made to control for place of articulation of the plosive, given the available words in Mongolian.

\begin{tabular}{ccccc}
\hline & /a/ & /a:/ & /J/ & / : \\
\hline TVT & patiar, tatax, & taatai & totio & tootoi \\
& patentlax & & & \\
TVD & padaan & taagüi & togoo & toogoor \\
TVR & palan,tavag, & paalan, & tomoo & toolol \\
& talaar & taamag & & \\
TVs & tasag & NA & tosox & toosoo \\
\hline
\end{tabular}

Table A.2: $\mathrm{C}_{1}$ fortis plosive in polysyllables

The inclusion of a trisyllabic word, in this case, is due to the lack of suitable disyllabic words in other comparisons of interest (see Tables A.1A.3). In total, three trisyllabic words were included in the dataset (batalgaa, patentlax, and sataarax).

As we can see in Tables A.4-A.7, the combinations available to explore the effects of $\mathrm{C}_{1}$ on aspiration properties of $\mathrm{C}_{2}$ are rather limited. Firstly, only fortis plosives and lenis plosives can be compared. Secondly, only some of the vowel phonemes are represented.

Again, we face some limitations of this subset of the data. Firstly, comparisons of the effect of /s/ can be made only for words with an intervening /a/. Secondly, tokens with /כ:/ are not represented here. 


\begin{tabular}{lllc}
\hline & $/ \mathrm{a} /$ & $/ \mathrm{J} /$ & $/ \mathrm{O} /$ \\
\hline TVT & tat & tot $^{\prime}$ & toot \\
DVT & bat & bot $^{\prime}$ & NA \\
\hline
\end{tabular}

Table A.3: $\mathrm{C}_{2}$ fortis plosive in monosyllables

\begin{tabular}{lccc}
\hline & /a/ & /a:/ & / / \\
\hline TVT & patiar, tatax & NA & totio \\
DVT & batalgaa & baatar & dotor \\
RVT & matar & maatan & motor \\
sVT & sataarax & NA & NA \\
\hline
\end{tabular}

Table A.4: $\mathrm{C}_{2}$ fortis plosive in polysyllables

\begin{tabular}{lccc}
\hline & /a/ & /a:/ & / :/ \\
\hline sVT & sataarax & saatax & sooton \\
sVD & sagax & saagix & NA \\
sVR & saryn & saaral & NA \\
sVs & NA & saasan & NA \\
\hline
\end{tabular}

Table A.5: $\mathrm{C}_{1}$ /s/ in polysyllables

\begin{tabular}{llll}
\hline & $/ \mathrm{a} /$ & $/ \mathrm{J} /$ & $/ \mathrm{\jmath} /$ \\
\hline TVs & tas & tos & toos \\
RVs & NA & NA & noos \\
\hline
\end{tabular}

Table A.6: $\mathrm{C}_{2} / \mathrm{s}$ / in monosyllables

\begin{tabular}{lcccc}
\hline & /a/ & /a:/ & /Ј/ & /כ:/ \\
\hline TVs & tasag & NA & tosox & toosoo \\
DVs & basax & baasan & bosox & boosox \\
RVs & nasos & maasaix & tomoo & noosoo \\
\hline
\end{tabular}

Table A.7: $\mathrm{C}_{1} / \mathrm{s} / \mathrm{in}$ polysyllables 


\section{Statistical analyses}

In the following tables, $\mathrm{T}$ = fortis stop, $\mathrm{D}=$ lenis stop, and $\mathrm{R}=$ sonorant; $\mathrm{F}=$ female, $\mathrm{M}=$ male, and syll. = syllables .

\section{Table A.8: Post-aspiration duration of $\mathrm{C}_{1}$ fortis plosive as a depend- ent variable}

The dependent variable in this model was the release duration of $\mathrm{C}_{1}$ fortis plosive. The analyses were therefore limited to those tokens whose $C_{1}$ is a fortis plosive. The following variables were entered in the final model as fixed effects: $\mathrm{C}_{2}$ type (four levels: fortis plosives, lenis plosives, sonorants, and /s/), vowel (four levels: /a/, /a:/, /o/, /o:/), sex (two levels: female, male), and number of syllables (three levels: monosyllabic, disyllabic, trisyllabic). As random effects, we had intercepts for speaker and word, as well as by-speaker random slopes for the effect of $\mathrm{C}_{2}$ type. Other models were tried (e.g. such that included an interaction between $\mathrm{C}_{2}$ type and the vowel phoneme), but these were less optimal than the model presented here.

$\begin{array}{lccccc} & \text { Estimate } & \text { Std. Error } & \mathrm{df} & \mathrm{t} \text { value } & \operatorname{Pr}(>|\mathrm{t}|) \\ \text { /a/vs /a:/ } & 6.609 & 4.321 & 25.540 & 1.529 & 0.13844 \\ \text { /a/ vs /J/ } & 3.175 & 3.198 & 25.010 & 0.993 & 0.33030 \\ \text { /a/ vs /J:/ } & 10.982 & 3.663 & 24.660 & 2.998 & 0.00612^{* *} \\ \mathrm{C}_{2} \text { /s/ vs T } & -7.913 & 4.125 & 23.950 & -1.918 & 0.06708 . \\ \mathrm{C}_{2} \text { /s/ vs D } & 1.679 & 4.865 & 22.910 & 0.345 & 0.73321 \\ \mathrm{C}_{2} \text { /s/ vs R } & 9.100 & 4.408 & 25.240 & 2.064 & 0.04942^{*} \\ 1 \text { vs. 2 syll. } & -6.602 & 2.495 & 44.940 & -2.646 & 0.01119^{*} \\ 1 \text { vs. 3 syll. } & -16.182 & 8.289 & 25.020 & -1.952 & 0.06220^{*} \\ \text { F vs. M } & -9.884 & 4.062 & 12.070 & -2.433 & 0.03145^{*}\end{array}$

Signif. codes: 0 '***' $0.001^{\prime * * \prime} 0.01^{\prime * \prime} 0.05$ ". $0.1^{\prime \prime} 1$

Table A.8: Post-aspiration duration of $\mathrm{C}_{1} \mathrm{~T}$ as a dependent variable

Table A.9: Post-aspiration occurrence of $C_{1} / s /$ as a dependent variable

The dependent variable in this model was the presence of post-aspiration in $\mathrm{C}_{1} / \mathrm{s} /$. The analyses were therefore limited to those tokens in which $\mathrm{C}_{1}$ is $/ \mathrm{s} /$. The following variables were entered in the final model as fixed 
effects: $\mathrm{C}_{2}$ type (four levels: fortis plosives, lenis plosives, sonorants, and /s/), vowel (four levels: /a/, /a:/, / /, /כ:/), sex (two levels: female, male). As random effects, we had intercepts for speaker and word, as well as byspeaker random slopes for the effect of $\mathrm{C}_{2}$ type.

\begin{tabular}{|c|c|c|c|c|}
\hline & Estimate & Std. Error & z value & $\operatorname{Pr}(>|z|)$ \\
\hline /a/vs /a:/ & -23.3609 & 68675.9561 & 0.000 & 1.000 \\
\hline /a/vs /ว/ & 0.4705 & 717.6816 & 0.001 & 0.999 \\
\hline /a/ vs /כ:/ & 8.5002 & 103.1154 & 0.082 & 0.934 \\
\hline $\mathrm{C}_{2} / \mathrm{s} / \mathrm{vs} \mathrm{T}$ & -35.8886 & 68676.0336 & 0.000 & 1.000 \\
\hline $\mathrm{C}_{2} / \mathrm{s} / \mathrm{vs} \mathrm{D}$ & -23.5642 & 68675.9562 & 0.000 & 1.000 \\
\hline $\mathrm{C}_{2} / \mathrm{s} / \mathrm{vs} \mathrm{R}$ & -38.8021 & 68678.3116 & -0.001 & 1.000 \\
\hline $\mathrm{F}$ vs $\mathrm{M}$ & 2.9482 & 3.2734 & 0.901 & 0.368 \\
\hline
\end{tabular}

Table A.9: Post-aspiration occurrence of $\mathrm{C}_{1}$ /s/ as a dependent variable

Table A.10: Post-aspiration duration (ms) of $C_{1} / s /$ as a dependent variable

The dependent variable in this model was the duration of post-aspiration in $\mathrm{C}_{1}$ /s/. Instances of post-aspiration duration of $0 \mathrm{~ms}$ are included, but the results do not change if they are excluded. The analyses were limited to those tokens whose $\mathrm{C}_{1}$ is $/ \mathrm{s} /$. The following variables were entered in the final model as fixed effects: $\mathrm{C}_{2}$ type (four levels: fortis plosives, lenis plosives, sonorants, and /s/), vowel (four levels: /a/, /a:/, / /,/כ:/), sex (two levels: female, male). As random effects, we had intercepts for speaker and word, as well as by-speaker random slopes for the effect of $\mathrm{C}_{2}$ type.

Table A.11: Post-aspiration occurrence of $\mathrm{C}_{2} / \mathrm{s} /$ as a dependent variable

The dependent variable in this model was the frequency of occurrence of post-aspiration of $\mathrm{C}_{2} / \mathrm{s} /$. The analyses were therefore limited to those tokens whose $\mathrm{C}_{2}$ is /s/. The following variables were entered in the final model as fixed effects: $\mathrm{C}_{1}$ type (four levels: fortis plosives, lenis plosives, sonorants, and /s/), vowel (four levels: /a/, /a:/, /כ/, /כ:/), sex (two levels: female, male), and number of syllables (three levels: monosyllabic, disyllabic, trisyllabic). As random effects, we had intercepts for speaker 


\begin{tabular}{|c|c|c|c|c|c|}
\hline & Estimate & Std. Error & $\mathrm{df}$ & t value & $\operatorname{Pr}(>|t|)$ \\
\hline /a/ vs /a:/ & 4.0440 & 3.0609 & 3.2650 & 1.321 & 0.2714 \\
\hline /a/ vs /כ/ & -0.3103 & 4.4244 & 3.6920 & -0.070 & 0.9477 \\
\hline /a/ vs /כ:/ & 6.4557 & 4.8796 & 2.9290 & 1.323 & 0.2796 \\
\hline $\mathrm{C}_{2} / \mathrm{s} / \mathrm{vs} \mathrm{T}$ & -1.1166 & 5.4677 & 4.1720 & -0.204 & 0.8478 \\
\hline $\mathrm{C}_{2} / \mathrm{s} /$ vs $\mathrm{D}$ & 1.4281 & 5.1945 & 3.6040 & 0.275 & 0.7984 \\
\hline $\mathrm{C}_{2} / \mathrm{s} / \mathrm{vs} \mathrm{R}$ & 7.6279 & 4.9323 & 3.4020 & 1.547 & 0.2091 \\
\hline F vs M & -1.1733 & 5.7871 & 7.2610 & -0.203 & 0.8449 \\
\hline
\end{tabular}

Table A.10: Post-aspiration duration (ms) of $\mathrm{C}_{1} / \mathrm{s} /$ as a dependent variable

and word, as well as by-speaker random slopes for the effect of $\mathrm{C}_{1}$ type. Other models were tried (e.g. such that included an interaction between $\mathrm{C}_{1}$ type and the vowel phoneme), but these did not yield any differences in the results.

$\begin{array}{lcccc} & \text { Estimate } & \text { Std. Error } & \mathrm{z} \text { value } & \operatorname{Pr}(>|\mathrm{z}|) \\ \text { /a/ vs /a:/ } & -1.06136 & 1.30517 & -0.813 & 0.416 \\ \text { /a/ vs /s/ } & 1.10708 & 1.18447 & 0.935 & 0.350 \\ \text { /a/ vs /J:/ } & 0.65479 & 1.03437 & 0.633 & 0.527 \\ \mathrm{C}_{1} \text { /s/vs T } & -1.35218 & 2.73713 & -0.494 & 0.621 \\ \mathrm{C}_{1} \text { /s/ vs D } & -2.03887 & 2.43017 & -0.839 & 0.401 \\ \mathrm{C}_{1} \text { /s/ vs R } & -1.74587 & 2.50984 & -0.696 & 0.487 \\ \text { F vs M } & 0.06697 & 1.29770 & 0.052 & 0.959\end{array}$

Signif. codes: 0 '***' $0.001^{\prime * * \prime} 0.01^{\prime * \prime} 0.05$ '. 0.1 ' ' 1

Table A.11: Post-aspiration occurrence of $\mathrm{C}_{2} / \mathrm{s} /$ as a dependent variable

Table A.12: Pre-aspiration occurrence of $\mathrm{C}_{2} / \mathrm{s} /$ as a dependent variable

The dependent variable in this model was the frequency of occurrence of pre-aspiration of $\mathrm{C}_{2} / \mathrm{s} /$. The analyses were therefore limited to those tokens whose $C_{2}$ is $/ \mathrm{s} /$. The following variables were entered in the final model as fixed effects: $\mathrm{C}_{1}$ type (four levels: fortis plosives, lenis plosives, sonorants, and /s/), vowel (four levels: /a/, /a:/,/э/, /э:/), sex (two levels: female, male), and number of syllables (three levels: monosyllabic, 
disyllabic, trisyllabic). As random effects, we had intercepts for speaker and word, as well as by-speaker random slopes for the effect of $\mathrm{C}_{1}$ type. Other models were tried (e.g. such that included an interaction between $\mathrm{C}_{1}$ type and the vowel phoneme), but these did not yield any differences in the results.

$\begin{array}{lcccc} & \text { Estimate } & \text { Std. Error } & \mathrm{z} \text { value } & \operatorname{Pr}(>|\mathrm{z}|) \\ \text { /a/ vs /a:/ } & 2.22314 & 0.83315 & 2.668 & 0.007622^{* *} \\ \text { /a/ vs /J/ } & 1.20323 & 0.55110 & 2.183 & 0.029011^{*} \\ \text { /a/ vs / :/ } & 2.71726 & 0.79508 & 3.418 & 0.000632^{* * *} \\ \mathrm{C}_{1} \text { /s/ vs fortis plosives } & -0.36603 & 2.36260 & -0.155 & 0.876879 \\ \mathrm{C}_{1} \text { /s/ vs lenis plosives } & -0.51744 & 2.30365 & -0.225 & 0.822276 \\ \mathrm{C}_{1} \text { /s/ vs sonorant } & 0.06228 & 2.37252 & 0.026 & 0.979056 \\ \text { F vs M } & -0.65524 & 0.56092 & -1.168 & 0.242744 \\ 1 \text { vs } 2 \text { syll. } & -1.52069 & 0.72278 & -2.104 & 0.035384\end{array}$

Signif. codes: 0 '***' $0.001^{\prime * * \prime} 0.01$ '*' 0.05 '. 0.1 ' ' 1

Table A.12: Pre-aspiration occurrence of $\mathrm{C}_{2} / \mathrm{s} /$ as a dependent variable

\section{Table A.13: Post-aspiration duration (ms) of $C_{2} / s /$ as a dependent variable}

The dependent variable in this model was the duration of post-aspiration in $\mathrm{C}_{2}$ /s/. Instances of post-aspiration duration of $0 \mathrm{~ms}$ are included. The analyses were limited to those tokens whose $\mathrm{C}_{2}$ is /s/. The following variables were entered in the final model as fixed effects: $\mathrm{C}_{1}$ type (four levels: fortis plosives, lenis plosives, sonorants, and /s/), vowel (four levels: /a/, /a:/, /Ј/, /э:/), sex (two levels: female, male), and number of syllables (three levels: monosyllabic, disyllabic, trisyllabic). As random effects, we had intercepts for speaker and word, as well as by-speaker random slopes for the effect of $\mathrm{C}_{1}$ type.

Table A.14: Pre-aspiration duration (ms) of $C_{2} / s /$ as a dependent variable

The dependent variable in this model was the duration of pre-aspiration in $\mathrm{C}_{2}$ /s/. Instances of post-aspiration duration of $0 \mathrm{~ms}$ are included. The analyses were limited to those tokens whose $\mathrm{C}_{2}$ is $/ \mathrm{s} /$. The following variables were entered in the final model as fixed effects: $\mathrm{C}_{1}$ type (four levels: fortis plosives, lenis plosives, sonorants, and /s/), vowel (four levels: /a/, 


$\begin{array}{lccccc} & \text { Estimate } & \text { Std. Error } & \mathrm{df} & \mathrm{t} \text { value } & \operatorname{Pr}(>|\mathrm{t}|) \\ \text { /a/vs /a:/ } & -0.5026 & 5.3241 & 4.7690 & -0.094 & 0.92863 \\ \text { /a/vs / / } & -1.6874 & 3.6195 & 4.1310 & -0.466 & 0.66459 \\ \text { /a/ vs / J: } & 7.2005 & 3.6567 & 4.3060 & 1.969 & 0.11525 \\ \mathrm{C}_{1} \text { /s/vs T } & 15.6535 & 7.5222 & 5.6440 & 2.081 & 0.08556 . \\ \mathrm{C}_{1} \text { /s/ vs D } & -14.8826 & 7.1698 & 7.1500 & -2.076 & 0.07573 . \\ \text { F vs M } & 7.3135 & 3.3103 & 6.0330 & 2.209 & 0.06896 . \\ \text { 1 vs 2 syll. } & -10.4767 & 3.4513 & 5.9710 & -3.036 & 0.02307^{*}\end{array}$

Signif. codes: 0 '***' $0.001^{\prime * * \prime} 0.01^{\prime * \prime} 0.05$ '. $0.1^{\prime \prime} 1$

Table A.13: Post-aspiration duration (ms) of $\mathrm{C}_{2} / \mathrm{s} /$ as a dependent variable

/a:/,/э/, /э:/), and sex (two levels: female, male). As random effects, we had intercepts for speaker and word, as well as by-speaker random slopes for the effect of $\mathrm{C}_{1}$ type.

$\begin{array}{lccccc} & \text { Estimate } & \text { Std. Error } & \mathrm{df} & \mathrm{t} \text { value } & \operatorname{Pr}(>|\mathrm{t}|) \\ \text { /a/ vs /a:/ } & -3.31041 & 2.13376 & 7.02200 & -1.551 & 0.165 \\ \text { /a/ vs / / } & -2.72721 & 1.85213 & 6.39100 & -1.472 & 0.188 \\ \text { /a/ vs / a:/ } & -3.90706 & 1.62801 & 6.70700 & -2.400 & 0.049 * \\ \mathrm{C}_{1} \text { /s/ vs T } & 0.04283 & 3.25582 & 7.00200 & 0.013 & 0.990 \\ \mathrm{C}_{1} \text { /s/ vs D } & 1.64904 & 3.15785 & 8.06400 & 0.522 & 0.616 \\ \mathrm{C}_{1} \text { /s/ vs R } & -0.10196 & 3.01610 & 6.49700 & -0.034 & 0.974 \\ \text { F vs M } & 0.86447 & 0.97316 & 12.40400 & 0.888 & 0.391\end{array}$

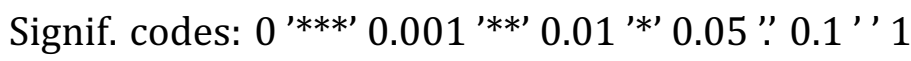

Table A.14: Pre-aspiration duration (ms) of $\mathrm{C}_{2} / \mathrm{s} /$ as a dependent variable

Table A.15: Breathiness occurrence prior to $C_{2} / s$ / as a dependent variable

The dependent variable in this model was the frequency of occurrence of vowel-final breathiness prior to $\mathrm{C}_{2} / \mathrm{s} /$. The analyses were therefore limited to those tokens whose $\mathrm{C}_{2}$ is /s/. The following variables were entered in the model as fixed effects: $\mathrm{C}_{1}$ type (four levels: fortis plosives, lenis plosives, sonorants, and /s/), vowel (four levels: /a/, /a:/, /כ/, /כ:/), sex (two levels: female, male), and number of syllables (three levels: monosyllabic, disyllabic, trisyllabic). As random effects, we had intercepts for 
speaker and word, as well as by-speaker random slopes for the effect of $\mathrm{C}_{1}$ type. Other models were tried (e.g. such that included an interaction between $\mathrm{C}_{1}$ type and the vowel phoneme), but these did not yield any differences in the results or were problematic because of the combinatorial characteristics of the dataset.

$\begin{array}{lcccc} & \text { Estimate } & \text { Std. Error } & \mathrm{z} \text { value } & \operatorname{Pr}(>|\mathrm{z}|) \\ \text { /a/ vs /a:/ } & -0.8302 & 1.3547 & -0.613 & 0.540 \\ \text { /a/ vs / / } & -1.3437 & 1.2571 & -1.069 & 0.285 \\ \text { /a/ vs / : } / ~ & -1.4918 & 1.2498 & -1.194 & 0.233 \\ \mathrm{C}_{1} \text { /s/ vs T } & 16.9707 & 6551.5338 & 0.003 & 0.998 \\ \mathrm{C}_{1} \text { /s/ vs D } & 16.3640 & 6551.5338 & 0.002 & 0.998 \\ \mathrm{C}_{1} \text { /s/ vs R } & 15.6180 & 6551.5338 & 0.002 & 0.998 \\ \mathrm{~F}_{\text {v } ~ M} & -0.2397 & 1.1881 & -0.202 & 0.840 \\ 1 \text { vs } 2 \text { syll. } & 0.7998 & 1.3148 & 0.608 & 0.543\end{array}$

Signif. codes: 0 '***' $0.001^{* * *} 0.01^{\prime * \prime} 0.05$ ". $0.1^{\prime \prime} 1$

Table A.15: Breathiness occurrence prior to $\mathrm{C}_{2} / \mathrm{s} /$ as a dependent variable

\section{Table A.16: Breathiness duration (ms) prior to $C_{2} / \mathrm{s} /$ as a dependent variable}

The dependent variable in this model was the duration of vowel-final breathiness prior to $\mathrm{C}_{2} / \mathrm{s} /$. Instances of post-aspiration duration of $0 \mathrm{~ms}$ are included. The analyses were limited to those tokens whose $\mathrm{C}_{2}$ is $/ \mathrm{s} /$. The following variables were entered in the model as fixed effects: $\mathrm{C}_{1}$ type (four levels: fortis plosives, lenis plosives, sonorants, and /s/), vowel (four levels: /a/, /a:/, /э/, /э:/), and sex (two levels: female, male). As random effects, we had intercepts for speaker and word, as well as byspeaker random slopes for the effect of $\mathrm{C}_{1}$ type. Other models were tried (e.g. such that included an interaction between $\mathrm{C}_{1}$ type and the vowel phoneme), but these did not yield any differences in the results or were problematic because of the data design.

\section{Table A.17: Release duration ( $\mathrm{ms}$ ) of $\mathrm{C}_{2}$ fortis plosive as a dependent variable}

The dependent variable in this model was the duration of the release of $\mathrm{C}_{2}$ fortis plosives. The analyses were limited to those tokens whose $\mathrm{C}_{2}$ is a fortis plosive. The following variables were entered in the model as 


$\begin{array}{lccccc} & \text { Estimate } & \text { Std. Error } & \mathrm{df} & \mathrm{t} \text { value } & \operatorname{Pr}(>|\mathrm{t}|) \\ \text { /a/vs /a:/ } & -3.31041 & 2.13376 & 7.02200 & -1.551 & 0.165 \\ \text { /a/ vs / / } & -2.72721 & 1.85213 & 6.39100 & -1.472 & 0.188 \\ \text { /a/ vs / } \mathrm{s} / & -3.90706 & 1.62801 & 6.70700 & -2.400 & 0.049 * \\ \mathrm{C}_{1} \text { /s/ vs T } & 0.04283 & 3.25582 & 7.00200 & 0.013 & 0.990 \\ \mathrm{C}_{1} \text { /s/vs D } & 1.64904 & 3.15785 & 8.06400 & 0.522 & 0.616 \\ \mathrm{C}_{1} \text { /s/ vs R } & -0.10196 & 3.01610 & 6.49700 & -0.034 & 0.974 \\ \text { F vs M } & 0.86447 & 0.97316 & 12.40400 & 0.888 & 0.391\end{array}$

Signif. codes: 0 '***' $0.001^{\prime * * \prime} 0.01^{\prime * \prime} 0.05$ '. $0.1^{\prime \prime} 1$

Table A.16: Breathiness duration (ms) prior to $C_{2} / s$ / as a dependent variable

fixed effects: $\mathrm{C}_{1}$ type (four levels: fortis plosives, lenis plosives, sonorants, and /s/), vowel (four levels: /a/, /a:/, /כ/, /כ:/), sex (two levels: female, male), and number of syllables (three levels: monosyllabic, disyllabic, trisyllabic). As random effects, we had intercepts for speaker and word. Other models were tried (e.g. such that included an interaction between $\mathrm{C}_{1}$ type and the vowel phoneme), but these did not yield any differences in the results or were problematic because of the data design.

$\begin{array}{lccccc} & \text { Estimate } & \text { Std. Error } & \mathrm{df} & \mathrm{t} \text { value } & \operatorname{Pr}(>|\mathrm{t}|) \\ \text { /a/vs /a:/ } & 4.143 & 4.124 & 10.583 & 1.005 & 0.3375 \\ \text { /a/vs / / } & 7.129 & 3.556 & 10.948 & 2.005 & 0.0703 . \\ \text { /a/vs /a:/ } & 8.384 & 4.283 & 10.244 & 1.957 & 0.0781 . \\ \mathrm{C}_{1} \text { /s/ vs T } & 3.792 & 4.263 & 11.567 & 0.889 & 0.3919 \\ \mathrm{C}_{1} \text { /s/ vs D } & 4.720 & 4.800 & 11.921 & 0.983 & 0.3450 \\ \mathrm{C}_{1} \text { /s/ vs R } & 1.503 & 5.259 & 11.237 & 0.286 & 0.7802 \\ \mathrm{~F}_{\text {vs M }} & -4.017 & 6.324 & 5.572 & -0.635 & 0.5505 \\ 1 \text { vs 2 syll. } & -64.700 & 3.293 & 12.488 & -19.646 & 9.14 \mathrm{e}-11^{* * *} \\ 1 \text { vs 3 syll. } & -59.736 & 4.769 & 12.064 & -12.526 & 2.83 \mathrm{e}-08^{* * *}\end{array}$

Signif. codes: 0 '***' $0.001^{\prime * * \prime} 0.011^{\prime * \prime} 0.05$ '. $0.1^{\prime \prime} 1$

Table A.17: Release duration (ms) of $\mathrm{C}_{2}$ fortis plosive as a dependent variable 
Table A.18: Pre-aspiration occurrence prior to $C_{2}$ fortis plosive as a dependent variable

The dependent variable in this model was the frequency of occurrence of pre-aspiration prior to $\mathrm{C}_{2}$ fortis plosives. The analyses were therefore limited to those tokens whose $C_{2}$ is a fortis plosive. The following variables were entered in the model as fixed effects: $\mathrm{C}_{1}$ type (four levels: fortis plosives, lenis plosives, sonorants, and /s/) with an interaction with vowel (four levels: /a/, /a:/, /כ/,/o:/), sex (two levels: female, male), and number of syllables (three levels: monosyllabic, disyllabic, trisyllabic). As random effects, we had intercepts for speaker and word, as well as byspeaker random slopes for the effect of $\mathrm{C}_{1}$ type. Other models were tried, but these did not yield any differences in the results or were problematic because of the data design.

\begin{tabular}{|c|c|c|c|c|}
\hline & Estimate & Std. Error & $\mathrm{z}$ value & $\operatorname{Pr}(>|z|)$ \\
\hline /a/vs /a:/ & 0.08643 & 1.08974 & 0.079 & 0.93678 \\
\hline /a/ vs / J/ & 2.22750 & 0.97303 & 2.289 & $0.02207 *$ \\
\hline /a/ vs /כ:/ & -0.45038 & 1.06488 & -0.423 & 0.67234 \\
\hline $\mathrm{C}_{1} / \mathrm{s} / \mathrm{vs} \mathrm{T}$ & -0.06737 & 0.87874 & -0.077 & 0.93889 \\
\hline $\mathrm{C}_{1} / \mathrm{s} / \mathrm{vs} \mathrm{D}$ & -1.73285 & 1.03727 & -1.671 & 0.09481 \\
\hline $\mathrm{C}_{1} / \mathrm{s} / \mathrm{vs} \mathrm{R}$ & -1.51699 & 1.24436 & -1.219 & 0.22281 \\
\hline F vs M & -1.56727 & 1.10476 & -1.419 & 0.15600 \\
\hline 1 vs 2 syll. & -1.24616 & 0.38648 & -3.224 & $0.00126^{* *}$ \\
\hline 1 vs 3 syll. & -0.47204 & 0.59395 & -0.795 & 0.42676 \\
\hline$/ \mathrm{a} /: \mathrm{C}_{1} / \mathrm{s} / \mathrm{vs} \mathrm{T}$ & -0.69901 & 1.18910 & -0.588 & 0.55663 \\
\hline$/ \mathrm{J} / \mathrm{C}_{1} / \mathrm{s} / \mathrm{vs} \mathrm{T}$ & -2.09511 & 1.10527 & -1.896 & 0.05802 . \\
\hline /ว:/: $\mathrm{C}_{1} / \mathrm{s} / \mathrm{vs} \mathrm{T}$ & 0.24617 & 1.13463 & 0.217 & 0.82824 \\
\hline /a:/: $\mathrm{C}_{1} / \mathrm{s} / \mathrm{vs} \mathrm{T}$ & 2.51535 & 1.23916 & 2.030 & $0.04237 *$ \\
\hline /э:/: $\mathrm{C}_{1} / \mathrm{s} /$ vs D & -1.89453 & 1.19972 & -1.579 & 0.11430 \\
\hline /a:/: $\mathrm{C}_{1} / \mathrm{s} / \mathrm{vs} \mathrm{R}$ & 0.73975 & 1.40485 & 0.527 & 0.59849 \\
\hline
\end{tabular}

Signif. codes: 0 '***' $0.001^{\prime * * \prime} 0.01^{\prime * \prime} 0.05$ '. $0.1^{\prime \prime} 1$

Table A.18: Pre-aspiration occurrence prior to $C_{2}$ fortis plosive as a dependent variable

This model represents the only instance in which there was a significant interaction between consonantal type and vowel length. Nowhere else in the statistical analyses or visual inspection (see e.g. Figure ?? for $\mathrm{C}_{1}$ fortis plosives) did we observe an interaction between consonant type and vowel length. This one exception is nevertheless complicated in that it only involves one of the vocalic short-long pairs: /a/ and /a:/. Further- 
more, in the short context, the difference comes down to $\mathrm{C}_{1} / \mathrm{s} / \mathrm{being}$ associated with slightly fewer cases of pre-aspiration $\mathrm{C}_{2}$ fortis plosive preaspiration occurrences than $\mathrm{C}_{2}$ fortis plosives, and in the long context, this is the other way round and the effect is larger.

Table A.19: Pre-aspiration duration (ms) of $\mathrm{C}_{2}$ fortis plosive as a dependent variable

The dependent variable in this model was the duration of the pre-aspiration of $\mathrm{C}_{2}$ fortis plosives. The analyses were limited to those tokens whose $\mathrm{C}_{2}$ is a fortis plosive. The following variables were entered in the model as fixed effects: $\mathrm{C}_{1}$ type (four levels: fortis plosives, lenis plosives, sonorants, and /s/), vowel (four levels: /a/, /a:/, / /, /כ:/), sex (two levels: female, male), and number of syllables (three levels: monosyllabic, disyllabic, trisyllabic). As random effects, we had intercepts for speaker and word, as well as by-speaker random slopes for the effect of $C_{1}$ type. Other models were tried (e.g. such that included an interaction between $\mathrm{C}_{1}$ type and the vowel phoneme), but these did not yield any differences in the results or were problematic because of the data design.

$\begin{array}{lccccc} & \text { Estimate } & \text { Std. Error } & \mathrm{df} & \mathrm{t} \text { value } & \operatorname{Pr}(>|\mathrm{t}|) \\ \text { /a/ vs /a:/ } & -4.5126 & 3.3899 & 13.3270 & -1.331 & 0.2054 \\ \text { /a/ vs / / } & -1.4620 & 2.8996 & 13.5860 & -0.504 & 0.6222 \\ \text { /a/ vs / / / } & -1.2979 & 3.5735 & 12.6250 & -0.363 & 0.7225 \\ \mathrm{C}_{1} \text { /s/ vs T } & 0.9156 & 3.4750 & 13.1700 & 0.263 & 0.7963 \\ \mathrm{C}_{1} \text { /s/ vs D } & 6.6400 & 4.4161 & 16.6860 & 1.504 & 0.1514 \\ \mathrm{C}_{1} \text { /s/ vs R } & 5.1960 & 4.9949 & 16.9350 & 1.040 & 0.3128 \\ \mathrm{~F}_{\text {vs M }} & 3.0063 & 1.8380 & 6.8770 & 1.636 & 0.1467 \\ 1 \text { vs 2 syll. } & 4.8430 & 2.3929 & 25.3410 & 2.024 & 0.0536 . \\ 1 \text { vs 3 syll. } & 1.2425 & 3.8102 & 13.7080 & 0.326 & 0.7493\end{array}$

Signif. codes: 0 '***' $0.001^{\prime * * \prime} 0.011^{\prime * \prime} 0.05$ '. 0.1 ' ' 1

Table A.19: Pre-aspiration duration ( $\mathrm{ms}$ ) of $\mathrm{C}_{2}$ fortis plosive as a dependent variable

Table A.20: Breathiness occurrence prior to $C_{2}$ fortis plosive as a dependent variable

The dependent variable in this model was the frequency of occurrence of local breathiness prior to $\mathrm{C}_{2}$ fortis plosives. The analyses were therefore limited to those tokens whose $\mathrm{C}_{2}$ is a fortis plosive. The following 
variables were entered in the model as fixed effects: $\mathrm{C}_{1}$ type (four levels: fortis plosives, lenis plosives, sonorants, and /s/), vowel (four levels: /a/, /a:/, /ว/, /э:/), sex (two levels: female, male), and number of syllables (three levels: monosyllabic, disyllabic, trisyllabic). As random effects, we had intercepts for speaker and word, as well as by-speaker random slopes for the effect of $\mathrm{C}_{1}$ type. Other models were tried, but these did not yield any differences in the results.

\begin{tabular}{|c|c|c|c|c|}
\hline & Estimate & Std. Error & $\mathrm{z}$ value & $\operatorname{Pr}(>|z|)$ \\
\hline /a/vs /a:/ & 1.88916 & 1.24358 & 1.519 & 0.12873 \\
\hline /a/vs /ग/ & 0.18731 & 0.97218 & 0.193 & 0.84722 \\
\hline /a/vs /כ:/ & 0.08482 & 1.10822 & 0.076 & 0.93899 \\
\hline $\mathrm{C}_{1} / \mathrm{s} / \mathrm{vs} \mathrm{T}$ & 0.75971 & 2.46017 & 0.309 & 0.75747 \\
\hline $\mathrm{C}_{1} / \mathrm{s} /$ vs $\mathrm{D}$ & -1.32974 & 3.11637 & -0.427 & 0.66960 \\
\hline $\mathrm{C}_{1} / \mathrm{s} / \mathrm{vs} \mathrm{R}$ & 1.53151 & 2.77022 & 0.553 & 0.58037 \\
\hline $\mathrm{F}$ vs $\mathrm{M}$ & -0.42073 & 1.05477 & -0.399 & 0.68998 \\
\hline 1 vs 2 syll. & -2.83269 & 1.07046 & -2.646 & $0.00814^{* *}$ \\
\hline 1 vs 3 syll. & -0.23259 & 1.04150 & -0.223 & 0.82328 \\
\hline
\end{tabular}

Table A.20: Breathiness occurrence prior to $C_{2}$ fortis plosive as a dependent variable

Table A.21: Breathiness duration (ms) prior to $\mathrm{C}_{2}$ fortis plosive as a dependent variable

The dependent variable in this model was the duration of the local breathiness prior to $\mathrm{C}_{2}$ fortis plosives. The analyses were limited to those tokens whose $\mathrm{C}_{2}$ is a fortis plosive. The following variables were entered in the model as fixed effects: $\mathrm{C}_{1}$ type (four levels: fortis plosives, lenis plosives, sonorants, and /s/), vowel (four levels: /a/, /a:/, /o/, /כ:/), sex (two levels: female, male), and number of syllables (three levels: monosyllabic, disyllabic, trisyllabic). As random effects, we had intercepts for speaker and word, as well as by-speaker random slopes for the effect of $\mathrm{C}_{1}$ type. Other models were tried (e.g. such that included an interaction between $\mathrm{C}_{1}$ type and the vowel phoneme), but these did not yield any differences in the results or were problematic because of the data design. 


$\begin{array}{lccccc} & \text { Estimate } & \text { Std. Error } & \mathrm{df} & \mathrm{t} \text { value } & \operatorname{Pr}(>|\mathrm{t}|) \\ \text { /a/vs /a:/ } & -3.240 & 4.185 & 11.013 & -0.774 & 0.45503 \\ \text { /a/ vs /J/ } & -1.242 & 3.610 & 11.470 & -0.344 & 0.73711 \\ \text { /a/ vs /o:/ } & -7.797 & 4.358 & 10.599 & -1.789 & 0.10220 \\ \mathrm{C}_{1} \text { /s/ vs T } & 5.684 & 4.272 & 11.233 & 1.331 & 0.20973 \\ \mathrm{C}_{1} \text { /s/ vs D } & 7.334 & 5.309 & 12.246 & 1.382 & 0.19180 \\ \mathrm{C}_{1} \text { /s/ vs R } & 7.002 & 5.432 & 11.208 & 1.289 & 0.22332 \\ \mathrm{~F} \text { vs M } & -8.948 & 5.640 & 6.354 & -1.586 & 0.16102 \\ 1 \text { vs 2 syll. } & 11.924 & 3.286 & 13.974 & 3.628 & 0.00275^{* *} \\ 1 \text { vs 3 syll. } & 16.420 & 4.734 & 11.494 & 3.469 & 0.00493 * *\end{array}$

Signif. codes: 0 '***' $0.001^{\prime * * \prime} 0.01^{\prime * \prime} 0.05$ ". $0.1^{\prime \prime} 1$

Table A.21: Breathiness duration (ms) prior to $C_{2}$ fortis plosive as a dependent variable

\section{References}

Allen, W. Sidney. 1957. Aspiration in the Harauti nominals. In Studies in Linguistic Analysis, London: Oxford University Press.

Bates, Douglas, Martin Maechler, Ben Bolker \& Steven Walker. 2014. lme4: Linear mixed-effects models using Eigen and S4. R package version 1.17. <http: //CRAN.R-project.org/package=lme4>.

Beguš, Gašper. 2016. The phonetics of aspirate dissimilation: Grassmann's Law in Georgian. Poster presented at The South Caucasian Chalk Circle, Paris.

Bennett, William. 2015. The phonology of consonants. Cambridge: Cambridge University Press.

Bermúdez-Otero, Ricardo. 2007. Diachronic phonology. In Paul de Lacy (ed.), The Cambridge handbook of phonology, 497-517. Cambridge: Cambridge University Press.

Bloomfield, Leonard. 1933. Language. London: G. Allen \& Unwin.

Boersma, Paul \& David Weenink. 2017. Praat: Doing phonetics by computer. <http://www . praat.org/>.

Egurtzegi, Ander. 2015. Towards a phonetically grounded diachronic phonology of Basque: University of the Basque Country dissertation.

Fox, John, Sanford Weisberg, Michael Friendly, Jangman Hong, Robert Andersen, David Firth, Steve Taylor \& R Core Team. 2017. Package "effects". Effect Displays for Linear, and Other Models. Version 4.0-0. <https: //cran.r-project.org/web/packages/effects/ effects.pdf $>$. 
Fraile, Rubén \& Juan I. Godino-Llorente. 2014. Cepstral peak prominence: a comprehensive analysis. Biomedical Signal Processing and Control 14. 42-54.

Gallagher, Gillian. 2010. The perceptual basis of long-distance laryngeal restrictions: MIT dissertation.

Gallagher, Gillian. 2016. Asymmetries in the representation of categorical phonotactics. Language 92(3). 557-590.

Garrett, Andrew. 2015. Sound change. In Claire Bowern \& Bethwyn Evans (eds.), The Routledge Handbook of Historical Linguistics, 227-248. Routledge.

Garrett, Andrew \& Keith Johnson. 2013. Phonetic bias in sound change. In Alan C. L. Yu (ed.), Origins of Sound Change: Approaches to Phonologization, 51-97. Oxford: Oxford University Press.

Georg, Stefan. 2003. Mongghul. In Juha Janhunen (ed.), The Mongolic languages, 286-306. London: Routledge.

Hejná, Míša. 2015. Pre-aspiration in Welsh English: A case study of Aberystwyth: University of Manchester PhD thesis.

Hejná, Míša. 2016. Pre-aspiration: manual on acoustic analyses 1.1. <http://ling. auf . net/lingbuzz/003184>.

Hillenbrand, James, Ronald A. Cleveland \& Robert I. Erickson. 1994. Acoustic correlates of breathy vocal quality. Journal of Speech and Hearing Research 37. 769-778.

Hock, Hans Heinrich \& Brian D. Joseph. 2009. Language History, Language Change, and Language Relationship. An Introduction to Historical and Comparative Linguistics. Berlin ; New York: Mouton de Gruyter 2nd edn.

Hoenigswald, Henry M. 1964. Minor sound changes. Phonetica 11. 202215.

Jatteau, Adèle. 2016. Le statut phonologique de l'aspiration en grec ancien: Université Paris 8 dissertation.

Jatteau, Adèle \& Míša Hejná. 2016. Dissimilation can be gradient: evidence from Aberystwyth English. Papers in Historical Phonology (PiHPh) 1. 359-386. <http://journals.ed.ac.uk/pihph/article/view/ $1737>$.

Karlsson, Anastasia Mukhanova \& Jan-Olof Svantesson. 2012. Aspiration of stops in Altaic languages: An acoustic study. Altai hakpo 22. 205222.

Kingston, John. 1990. Articulatory binding. In John Kingston \& Mary E. Beckman (eds.), Papers in Laboratory Phonology I. Between the Grammar and the Physics of Speech, 406-434. Cambridge: Cambridge University Press. 
Kiparsky, Paul. 1995. The phonological basis of sound change. In John A. Goldsmith (ed.), The Handbook of Phonological Theory, 640-670. 0xford: Blackwell.

Kuznetsova, Alexandra. 2015. lmerTest: Tests in Linear Mixed Effects Models. Version 2.0- 25. <http://cran.r-project.org/web/ packages/lmerTest/index.html>.

Lejeune, Michel. 1972. Phonétique historique du mycénien et du grec ancien. Paris: Klincksieck.

Lotto, Andrew J., Lorie L. Holt \& Keith R. Kluender. 1997. Effect of voice quality on perceived height of English vowels. Phonetica 54(2). 76-93.

MacEachern, Margaret R. 1999. Laryngeal Cooccurrence Restrictions Outstanding Dissertations in Linguistics. Garland Publishing.

Matlab. 2016. <https://www. mathworks.com/products/new_ products/release2016b.html $>$.

Morris, Jonathan \& Míša Hejná. in press. Pre-aspiration in Bethesda Welsh: a sociophonetic analysis. Journal of the International Phonetic Association .

Mostaert, Antoine \& A. de Smedt. 1930. Le Dialecte Monguor parlé par les Mongols du Kansu Occidental. Ière Partie: Phonétique. (Suite). Anthropos 25(3-4). 657-669.

Nance, Claire \& Jane Stuart-Smith. 2013. Pre-aspiration and postaspiration in Scottish Gaelic stop consonants. Journal of the International Phonetic Association 43(2). 129-152.

Ní Chasaide, Ailbhe. 1985. Preaspiration in phonological stop contrasts: University College of North Wales PhD thesis.

Ohala, John J. 1987. Experimental Phonology. In Proceedings of the Annual Meeting, Berkeley Linguistic Society, vol. 13, 202-227. Berkeley (CA).

Orr, Carolyn \& Robert E. Longacre. 1968. Proto-Quechumaran. Language 44(3). 528-555.

Osthoff, Hermann \& Karl Brugmann. 1878. Morphologische Untersuchungen auf dem Gebiete der indogermanischen Sprachen. Leipzig: S. Hirzel.

Paul, Hermann. 1920. Prinzipien der Sprachgeschichte. Halle: Niemeyer 5 th edn.

R Core Team. 2009-2015. R: A language and environment for statistical computing. <http://www.R-project.org/>, <http://www.rstudio. com>.

de Reuse, Willem J. 1981. Grassmann's Law in Ofo. International Journal of American Linguistics 47(3). 243-44.

Shue, Yen-Liang. 2010. The voice source in speech production: data, analysis and models: UCL PhD thesis. 
Shue, Yen-Liang, Pat Keating, Chad Vicenik \& Kristine Yu. 2011. Voicesauce: a program for voice analysis. 17th ICPhS, Hong Kong 1846-1849.

Suzuki, Keiichiro. 1998. A typological investigation of dissimilation: University of Arizona dissertation.

Svantesson, Jan-Olof \& Anastasia Mukhanova Karlsson. 2012. Preaspiration in Modern and Old Mongolian. Suomalais-Ugrilaisen Seuran Toimituksia (Mémoires de la Société Finno-Ougrienne) 264. 453-464.

Svantesson, Jan-Olof, Anna Tsendina, Anastasia Mukhanova Karlsson \& Vivan Franzén. 2005. The Phonology of Mongolian. Oxford: Oxford University Press.

Vaux, Bert. 1998. The laryngeal specifications of fricatives. Linguistic Inquiry 29(3). 497-511.

Weiss, Michael L. 2009. Outline of the historical and comparative grammar of Latin. Ann Arbor: Beech Stave Press. 